\title{
Navigating the Cytoplasm: Delivery of the Alphaherpesvirus Genome to the Nucleus
}

\author{
Gregory A. Smith* \\ Department of Microbiology-Immunology, Northwestern University Feinberg \\ School of Medicine, Chicago, IL, USA \\ *g-smith3@northwestern.edu
}

DOI: https://doi.org/10.21775/cimb.041.171

\begin{abstract}
Herpesviruses virions are large and complex structures that deliver their genetic content to nuclei upon entering cells. This property is not unusual as many other viruses including the adenoviruses, orthomyxoviruses, papillomaviruses, polyomaviruses, and retroviruses, do likewise. However, the means by which viruses in the alphaherpesvirinae subfamily accomplish this fundamental stage of the infectious cycle is tied to their defining ability to efficiently invade the nervous system. Fusion of the viral envelope with a cell membrane results in the deposition of the capsid, along with an assortment of tegument proteins, into the cytosol. Establishment of infection requires that the capsid traverse the cytosol, dock at a nuclear pore, and inject its genome into the nucleoplasm. Accumulating evidence indicates that the capsid is not the effector of this delivery process, but is instead shepherded by tegument proteins that remain capsid bound. At the same time, tegument proteins that are released from the capsid upon entry act to increase the susceptibility of the cell to the ensuing infection. Mucosal epithelial cells and neurons are both susceptible to alphaherpesvirus infection and, together, provide the niche to
\end{abstract}


which these viruses have adapted. Although much has been revealed about the functions of de novo expressed tegument proteins during the late stages of assembly and egress, this review will specifically address the roles of tegument proteins brought into the cell with the incoming virion, and our current understanding of alphaherpesvirus genome delivery to nuclei.

\section{Introduction}

For many viruses, replication in epithelial cells lining the respiratory or gastrointestinal tracts amplifies and releases viral particles back into the environment during an acute infection. Although neuroinvasive viruses of the alphaherpesviridae subfamily similarly replicate in epithelial cells at exposed mucosal sites, they subsequently spread to innervating axons of sensory and autonomic neurons, which is followed by their retrograde axonal transport to neural soma resident in peripheral nervous system (PNS) ganglia. Whereas members of the beta and gammaherpesvirus subfamilies transmit between tissues by modulating receptor use (Borza and Hutt-Fletcher, 2002; Scrivano et al., 2011), the neuroinvasive alphaherpesviruses engage host receptors that are ubiquitously expressed. Despite this relative lack of selectivity, infections typically progress in a controlled manner whereby viruses productively infect mucosal epithelial cells and generally establish latent infections in the PNS. Although the ability to infect the nervous system by an axonal route is uncommon, alphaherpesviruses are uniquely proficient at it, and yet the ensuing infections are usually asymptomatic. In other words, these neurotropic viruses are highly neuroinvasive yet typically not neurovirulent. Nonetheless, these neuroinvasive infections can cause diseases associated with high morbidity and mortality. For example, herpes simplex keratitis and herpes simplex encephalitis in humans caused by herpes simplex virus type 1 (HSV-1), post-herpetic neuralgia in humans caused by varicella zoster virus (VZV), Aujeszky's disease in pigs and severe pruritus in cows caused by pseudorabies virus (PRV), equine herpes myeloencephalopathy in horses caused by equine herpesvirus 1 (EHV-1), and encephalitis in cows caused by bovine herpesvirus 5 (BHV-5). 
Multiple infectious agents sporadically gain access to the nervous system by a hematogenous route, whereas poliovirus and rabies virus are examples of viruses that invade the nervous system axonally. However, unlike alphaherpesviruses, retrograde axonal transport of poliovirus and rabies virus often results in severe or fatal neurological disease (Ohka et al., 1998; Ren and Racaniello, 1992). Furthermore, the neuroinvasive ability of the latter two viruses is dependent upon tissue damage, presumably at neuromuscular junctions. Poliovirus is normally an enteric pathogen that rarely becomes neuroinvasive: an event that can be provoked by coincidental tissue damage such as that obtained by a needle injection (aka provocation poliomyelitis) (Gromeier and Wimmer, 1998). In the case of rabies virus, infection is typically initiated by an animal bite, which is an explicit tissue damage provocation. Both poliovirus and rabies virus are endocytosed at motor nerve endings and are transported retrogradely in axons within endosomes (Gluska et al., 2014; Lewis et al., 2000; Ohka et al., 2004; Salinas et al., 2010). Axons up-regulate retrograde axonal trafficking when damaged (Curtis et al., 1993; Hanz et al., 2003), which may inadvertently promote provocation-based invasion of these viruses. In contrast, alphaherpesviruses do not appear to require provocation as evidenced by the remarkably high incidence of these viruses in their respective host populations. In fact, rather than promoting neuroinvasion axon damage hinders alphaherpesvirus invasion of neurons, indicating that the mechanism used by alphaherpesviruses to engage retrograde axonal transport competes with the axon damage response rather than being supported by it (Koyuncu et al., 2013a). Coincident with these observations, alphaherpesvirus axonal trafficking is not reliant on endosomes but rather is mediated by direct viral engagement of the host cytoskeletal transport machinery in the cytosol (Antinone and Smith, 2006, 2010; Granzow et al., 1997; Luxton et al., 2005; Lycke et al., 1984). Therefore, deciphering the proficiency of alphaherpesvirus neuroinvasion requires knowledge of the fundamental process by which these viruses deliver their genomes to nuclei and the transport effectors that reside in a protein matrix located between the capsid and envelope: a structural referred to as the herpesvirus tegument. 


\section{Virion structure and ancestry}

The virion structure is a defining characteristic of the Herpesvirales order. At 200-250 nm in diameter, the viral particles are slightly too small to be spatially resolved with a light microscope, but their architecture becomes apparent when viewed by electron microscopy (Morgan et al., 1953; Stackpole, 1969). Virions consist of an icosahedral capsid shell containing the viral genome, surrounded by tegument that, in turn, is enveloped by a lipid bilayer covered in glycoprotein spikes. There are roughly 700 spikes in the HSV-1 envelope (Grunewald et al., 2003). Upon contact with a susceptible cell, the viral particle undergoes a series of architectural rearrangements that coordinate capsid entry into the cell and its subsequent transport through the cytoplasm to the nucleus.

Herpesviruses are notable for being the only members of the Duplodnaviria that infect animals (Figure 1) (Baker et al., 2005; Duda et al., 2006; Krupovic and Koonin, 2017; Suhanovsky and Teschke, 2015; Twarock and Luque, 2019; Wikoff et al., 2000). This recently classified realm consists of viruses possessing a capsid shell based on a HK97-type major capsid protein (International Committee on Taxonomy of Viruses). Other Duplodnaviria include the tailed bacteriophage (Caudovirales) that, like herpesviruses, have large dsDNA genomes packaged into preassembled procapsid shells by an ATP-fueled motor (Heming et al., 2014; Newcomb et al., 1996; Poon and Roizman, 1993; Trus et al., 1996; Wikoff et al., 2000). The capsid shell of HK97-type viruses consists of varying numbers of capsomers that are reinforced at points of three-fold symmetry, a function that in herpesviruses is performed by the capsid triplex proteins (Dai and Zhou, 2018; Yuan et al., 2018). Genome packaging occurs through a portal, located at one of the twelve capsid vertices where a penton capsomer would otherwise reside (Dedeo et al., 2019; Kornfeind and Visalli, 2018; McElwee et al., 2018; Newcomb et al., 2001). In phages, the portal is often accompanied by a tail that extends from this unique capsid vertex. Because of the asymmetry in particle morphology that the tail provides, it is clear that the phage portal vertex also serves as the exit channel during genome release. Although there is evidence that 


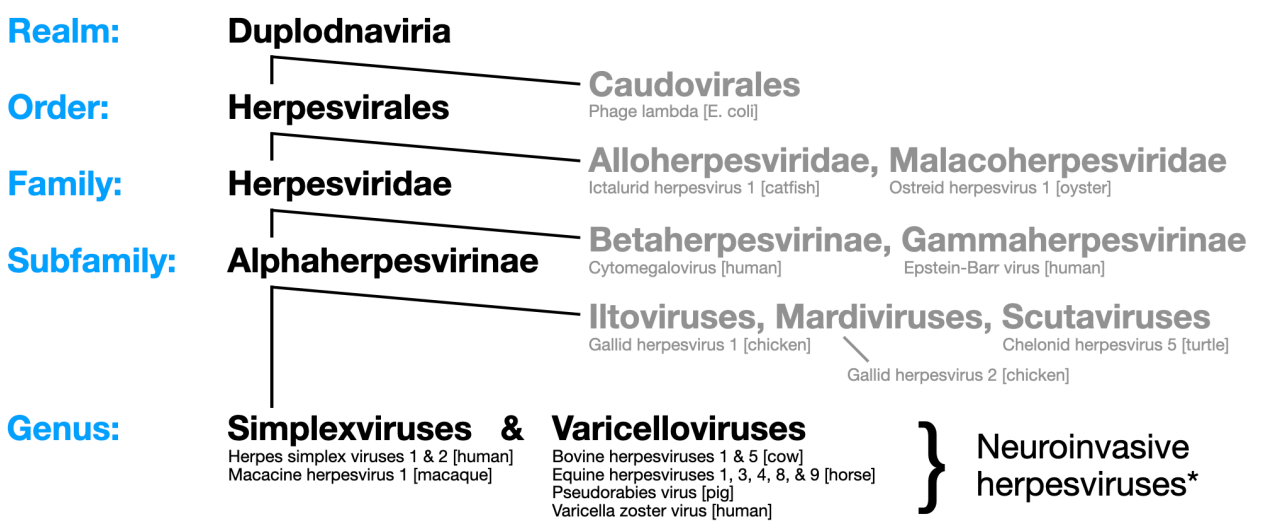

Figure 1. The neuroinvasive herpesviruses consist of members of the simplexvirus and varicellovirus genera. Divergent branches are shown in grey. Example species are shown below each classification with respective hosts in brackets. "There is evidence that iltoviruses may also be neuroinvasive (Williams et al., 1992).

herpesviruses capsids in extracellular virions have tails, such a structure has not been observed on capsids after entry into cells (Schmid et al., 2012).

The capsid interior consists primarily of the genome confined at high pressure, similarly to tailed bacteriophages (Bauer et al., 2013). The maturation protease, VP24, is the only protein known to reside with the genome inside the capsid shell (Kramer et al., 2011; Loret et al., 2008; Person and Desai, 1998; Sheaffer et al., 2001; Spear and Roizman, 1972; Stevenson et al., 1997). VP24 cleaves the protein scaffold that resides inside the capsid prior to genome packaging, allowing the genome to displace the scaffold from the capsid interior (Newcomb et al., 1996; Newcomb et al., 2000; Rixon and McNab, 1999). Despite a suggestion that VP24 could promote genome release from capsids, there is no evidence that VP24 contributes to initial infection (Jovasevic et al., 2008). 
The alphaherpesvirus capsid shell consists of the HK97-type major capsid protein, VP5, arranged in 162 capsomers consisting of 150 hexons and 11 pentons, the latter occupying the vertices (triangulation number of 16), with the twelfth vertex consisting of a ring of 12 copies of pUL 6 that forms the portal (Cardone et al., 2007). Each copy of VP5 contributing to hexons is capped by the small capsid protein, VP26, such that there are 955 copies of VP5 per capsid and 900 copies of VP26. The capsomers are oriented tip-to-tip instead of side-to-side, with the resulting gaps occupied by the triplex proteins VP19c and VP23 (Newcomb et al., 1993). The pentons provide rigidity to the capsid and are reinforced by pUL17 and pUL25 (Roos et al., 2009; Snijder et al., 2017), which together with the pUL36 tegument protein form five elongated structures that radiate from the pentons to the neighboring triplexes (Fan et al., 2014; Huet et al., 2016; Liu et al., 2017; Toropova et al., 2011; Trus et al., 2007). The pUL17/pUL25/pUL36 structure has been referred to as the Ccapsid-specific component (CCSC), the capsid-vertex-specific component (CVSC), and the capsid-associated tegument complex (CATC).

Unlike tailed bacteriophages, herpesvirus virions have a tegument and an envelope in addition to the capsid (Owen et al., 2015). The majority of the tegument mass departs from the icosahedral symmetry of the underlying capsid; therefore, unlike the capsid, much of the tegument and the envelope are not constrained by a rigid architecture (Zhou et al., 1999). The interface between the alphaherpesvirus capsid and tegument resides at the capsid vertices, but the composition of this interface is not yet fully elucidated (Zhou et al., 1999). Part of this interface consists of the interaction between pUL17/ pUL25 and the carboxyl terminus of the large tegument protein, pUL36 (Coller et al., 2007; Pasdeloup et al., 2009; Uetz et al., 2006). In a recent advance, the pUL17/pUL25/pUL36 interface was visualized and identified by cryo-electron microscopy at capsid vertices (Dai and Zhou, 2018; Liu et al., 2017; Wang et al., 2018). Although pUL36 is the only tegument protein for which a molecular interaction with the capsid is defined, the pUL16 tegument protein also associates with capsids (Meckes and Wills, 2007). Whether pUL16 binds a capsid protein directly or if its interaction is dependent on pUL36 has not been 
determined. Other tegument proteins are also reported to bind capsid proteins, including pUL21 (de Wind et al., 1992; Takakuwa et al., 2001), pUL37 (Lee et al., 2008; Uetz et al., 2006), and pUL47 (Scholtes et al., 2010), but it is not clear that these tegument proteins directly bind to assembled capsids. In fact, multiple lines of evidence argue against a direct interaction between pUL37 and capsids, with pUL37 instead tethered to capsids by pUL36 (Cardone et al., 2012; Daniel et al., 2018; Fuchs et al., 2004; Ko et al., 2010; Sandbaumhuter et al., 2013). Nevertheless, there is indirect evidence of additional capsidtegument interactions, including that virions can form to some degree in the absence of the pUL36-pUL25 interaction (Coller et al., 2007; Schipke et al., 2012), and that the link between pUL36 and the remainder of the tegument is also dispensable for virion formation (Fuchs et al., 2002; Svobodova et al., 2012).

Quantitative fluorescence imaging of individual alphaherpesvirus extracellular particles indicates that pUL36 is present at 5 copies at all 12 vertices along with its binding partner, pUL37 (Bohannon et al., 2013). However, the carboxylterminal capsid-binding domain of pUL36 is separated from the bulk of the protein by a linker region that is high in proline content and likely unstructured (Böttcher et al., 2006). Therefore, the majority of pUL36 along with the entirety of pUL37, which binds near the amino terminus of pUL36 (Klupp et al., 2002; Vittone et al., 2005), may have some freedom of movement while anchored to the capsid (Newcomb and Brown, 2010). This is consistent with symmetrydependent cryo-electron microscopy reconstructions of the capsid that have failed to resolve pUL36 apart from its carboxyl terminus (Dai and Zhou, 2018; Wang et al., 2018). In addition to pUL37, pUL36 tethers the pUS3 protein kinase to the capsid (Daniel et al., 2018) and links to the remainder of the tegument through an interaction with the pUL48 tegument protein (Ko et al., 2010; Svobodova et al., 2012). The pUL36 interaction with pUL48 appears complex, with pUL48 possibly undergoing a substantial conformational change as a result of binding to pUL36 (Svobodova et al., 2012). The significance of this is unknown, but unlike pUS3 and pUL37, pUL48 disassociates from capsids upon cell entry (Aggarwal et al., 2012; Antinone and Smith, 2010; 
Granzow et al., 2005; Luxton et al., 2005), hinting that the complexity of the pUL36-pUL48 interaction may be related to its metastability. Based on this accumulated knowledge, pUL36 is a central determinant to tegument disassembly upon cell entry and is currently the only known link between the capsid and the remainder of the tegument (Figure 2).

The envelope is the effector of cell entry, which occurs by its fusion with a cellular membrane. There are at least a dozen types of proteins in the

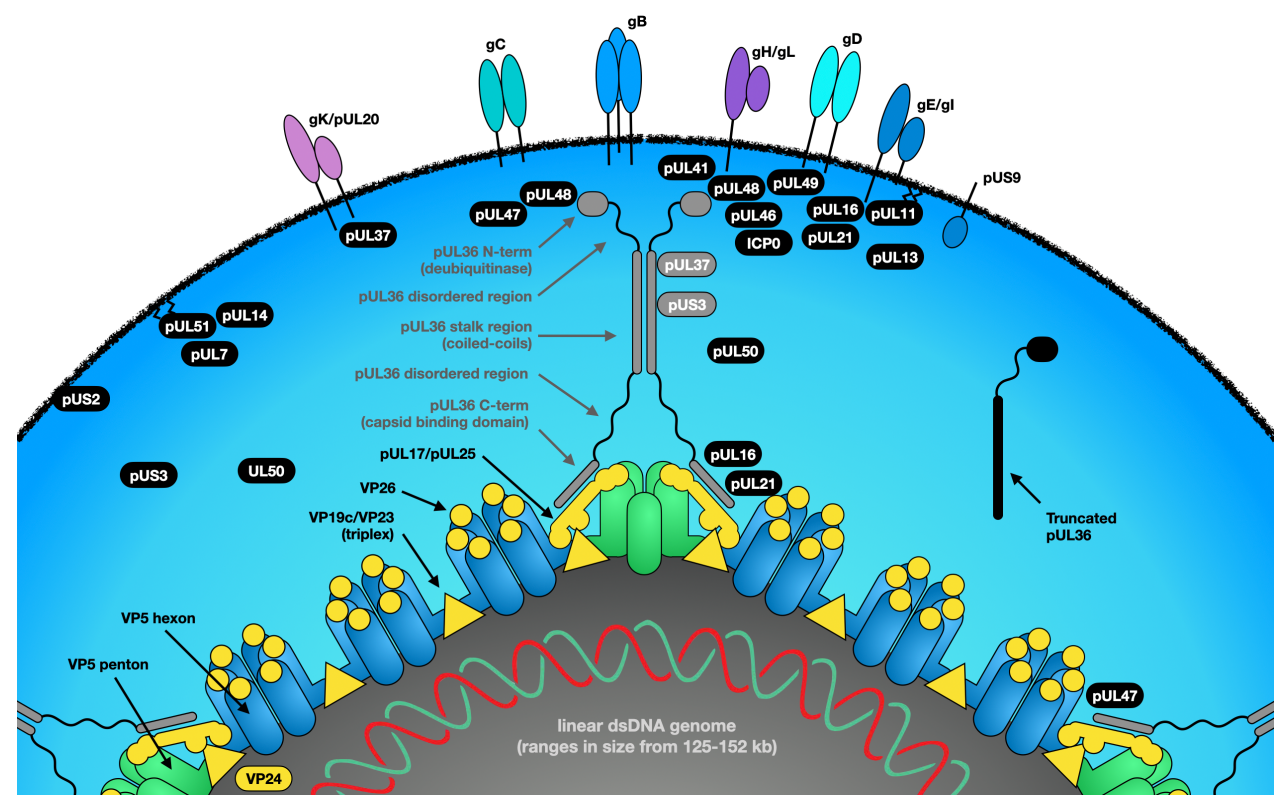

Figure 2. Components of the alphaherpesvirus virion. The icosahedral capsid (cut off at bottom) consists of hexons (blue) and pentons (green) of the major capsid protein, VP5. Other capsid proteins are shown in yellow. The capsid portal is not illustrated. Two of the five pUL17/pUL25/pUL36 copies per vertex are shown for simplicity. The large tegument protein, pUL36, is prominently featured and is shaded gray along with its binding partners, pUL37 and pUS3, which together are retained on the capsid following entry into a cell. Additional tegument proteins (black) are juxtaposed to known binding partners, including envelope proteins, with pUL48 linking the bulk of the tegument to the pUL36 amino terminus. However, unlike the capsid, the precise architectural arrangement of the tegument is largely unknown. The tegument also contains an assortment of cellular proteins and RNA that are not illustrated (Kramer et al., 2011; Loret et al., 2008; Sciortino et al., 2001). 
alphaherpesvirus envelope. In addition to driving entry, these proteins protect the virion from complement and antibody neutralization (Frank and Friedman, 1989; Hook et al., 2008; Komala Sari et al., 2020a), trigger alterations in the tegument architecture prior to entry (Meckes and Wills, 2008), and modulate the entry process (El Kasmi and Lippe, 2014; Komala Sari et al., 2020b).

\section{Virion disassembly and the post-entry capsid complex}

Virion attachment to cells triggers signaling events both into the cell and the virion. Signaling into the cell can be induced by the epidermal growth factor receptor and the virion envelope glycoproteins $\mathrm{B}(\mathrm{gB})$ and $\mathrm{gD}$, which activate cellular phosphoinositide 3-kinase (PI3K) (Cheshenko et al., 2013; Zheng et al., 2014). PI3K produces phosphatidylinositol $(3,4,5)$-trisphosphate $\left(\mathrm{PIP}_{3}\right)$ in the cell membrane that recruits pleckstrin-homology domain containing proteins and induces several signaling cascades. Activation of Akt, Cdc42, RhoA>ROCK1, and Erk1/2 are each reported to promote virus entry (Frampton et al., 2007; Hoppe et al., 2006; Oh et al., 2010; Tiwari and Shukla, 2010; Zheng et al., 2014); however, these signaling effects are not consistently observed in all studies (Devadas et al., 2014; Nicola and Straus, 2004). Nevertheless, one consequence of these events is the phosphorylation and inactivation of the actin-depolymerization protein, cofilin, the result of which may cluster receptors in proximity to the virion by promoting actin polymerization underneath the cell membrane (Van den Broeke et al., 2014; Zheng et al., 2014). NF-kB signaling can also result from PI3K/Akt activation. HSV-1, though interestingly not PRV, relies on NF-kB to establish infection and upon entering the cell reinforces NF-kB signaling using a TRAF6 effector domain carried in the HSV-1 pUL37 tegument protein (Liu et al., 2008; Patel et al., 1998; Romero et al., 2020). Why NF-kB is important for HSV-1 but not PRV is unclear, but the absence of an obvious TRAF6 effector domain in PRV pUL37 adds further support that NF-kB signaling is inconsequential to PRV. $\mathrm{PI3K} / \mathrm{Akt}$ signaling also triggers calcium release from the endoplasmic reticulum, which regulates cytoskeletal dynamics and may prime capsid trafficking to nuclei upon entry (Liu and Cohen, 2015; Nicola and Straus, 2004). 
Signaling that propagates into the virion before entry triggers release of pUL16 from the capsid (Meckes and Wills, 2008). The ramifications of this molecular event are not established but the finding demonstrates that the tegument is malleable. The plasticity of the tegument is also evident in ultrastructural studies. Newly formed virions are symmetric, with a tegument layer that is wrapped evenly around the capsid (Chen et al., 2004; Granzow et al., 1997), and which can be extracted from the capsid with nonionic detergent (Newcomb and Brown, 2009). The tegument architecture spontaneously redistributes over a period of 1-2 days such that the tegument mass is displaced predominantly to one side the capsid and becomes resistant to detergent extraction (Newcomb and Brown, 2009). Particles with spontaneous tegument displacement have been described in detail by transmission electron microscopy, cryo-electron tomography, and fluorescence ensemble mapping (Bohannon et al., 2013; Grunewald et al., 2003; Newcomb and Brown, 2009). Notably, the displaced tegument architecture is consistently observed when virions are in contact with uninfected cells, suggesting that cell contact can trigger the architectural change if it has not already occurred. Furthermore, the bulk of the tegument mass is specifically displaced to the side of the capsid facing away from the contacted cell (Fuller et al., 1989; Maurer et al., 2008). These events are hypothesized to prepare the virion for fusion and release of the capsid into the cytosol (Smith, 2017). Therefore, signals propagated into the virion and cell may act cooperatively to prime the ensuing infection.

Fusion of the herpesvirus envelope with a target cellular membrane, either the plasma membrane or the membrane of an endocytic vesicle, deposits the capsid and the tegument into the cell cytosol. What happens next was long shrouded in mystery. Early electron microscopy studies revealed that capsids deposited into the cytosol relocalize to the outer surface of nuclei where they release their genetic content: the electron-dense genome core notably absent from capsids docked on nuclear pores (Batterson et al., 1983; Granzow et al., 1997; Lycke et al., 1988). However, a series of events must occur before the 125-nm capsid, which is too large to passively diffuse to the nucleus, can reach its destination (Luby-Phelps, 1994, 2000). This begins with the release of 
the incoming capsid from the membrane and the disassembly of the majority of the tegument. As noted earlier, the latter begins with release of pUL16 from the capsid prior to entry into the cell (Meckes and Wills, 2008). Subsequent exposure to the cytosol likely allows the pUS3 and pUL13 tegument protein kinases to further drive this process, as has been inferred from in vitro studies (Morrison et al., 1998). The liberated tegument proteins rapidly manipulate cellular processes prior to nuclear genome delivery and viral gene expression. The first recognized effector functions of virion-delivered tegument proteins were the virion host shutoff (VHS) function of pUL41 and the transcriptional activation function of pUL48 (aka VP16, alphaTIF, Vmw65). This recognition was achieved by several experimental approaches including demonstration that UV-inactivated virions, which enter cells but do not express viral gene products, delivered these activities into cells (Ace et al., 1989; Batterson and Roizman, 1983; Fenwick and Walker, 1978; Nishioka and Silverstein, 1978).

Not all tegument proteins disassociate from capsids upon entry. The cytosolic capsid along with the subset of tegument proteins that remain capsid bound collectively make up what will be referred to here as the post-entry capsid complex (PECC). The tegument proteins of the PECC likely contribute to electron-dense material seen on capsid vertices following entry into cells (Sodeik et al., 1997). At least three tegument proteins are constituents of the PECC: pUL36, pUL37, and pUS3 (shown in gray in Figure 2). Retention of each of these tegument proteins on capsids was demonstrated by immunogold electron microscopy and by live-cell imaging of recombinant fluorescent viruses for HSV-1 and PRV (Aggarwal et al., 2012; Antinone and Smith, 2010; Coller and Smith, 2008; Granzow et al., 2005; Luxton et al., 2005). Thus, the composition of the PECC is conserved in these representative members of the simplexvirus and varicellovirus genera (Figure 1). Each of the known tegument constituents of the PECC has enzymatic activity: pUL36 has a deubiquitinase (DUB) domain in its amino terminus (Kattenhorn et al., 2005), pUL37 has a deamidase activity (Zhao et al., 2016), and pUS3 is a serine/threonine protein kinase (Frame et al., 1987; Purves et al., 1987). While these activities are noteworthy, they do not account for all of the functions of these proteins (Lee et 
al., 2006; Stults and Smith, 2019; Tian et al., 2018). The isolation of a temperature-sensitive mutant of HSV-1, which was subsequently mapped to the gene encoding pUL36, provided an early insight into one aspect of the PECC: at the non-permissive temperature, genomes were not released from capsids upon arriving at nuclear pores (Abaitua et al., 2011; Abaitua et al., 2009; Batterson et al., 1983).

Subsequent studies of the PECC were aided by producing recombinant viruses expressing fluorescent proteins fused to capsid components, which allowed for monitoring capsid dynamics and composition in living cells. The first such reporter virus encoded the green-fluorescent protein (GFP) fused to VP26 (Desai and Person, 1998). GFP-VP26 fusions are useful for studying initial infection because they offer bright fluorescence; however, they impair virus assembly and egress from nuclei during late infection (Bohannon et al., 2012; Krautwald et al., 2008; Nagel et al., 2012). A more recent deign that places GFP on the carboxyl-terminus of VP26 offers improved preservation of viral activity (Hogue et al., 2018). A subsequent design fused a fluorescent protein to pUL25, which offered a good balance between fluorescent emissions and low impact on virus replication (Bohannon et al., 2012; Conway et al., 2010). Whereas pUL25 and VP26 are surface-exposed capsid components, a more recent approach fused a fluorescent protein to the capsid maturation protease, VP24, which resides inside the capsid shell (Maier et al., 2016). Although VP24 fusions are 3-fold dimmer than pUL25 fusions, which are in turn 4-fold dimmer than VP26 fusions, they mitigate concerns that the fluorescent protein may interfere with capsid-tegument and capsid-host interactions. While fluorescence imaging has been used to gain structural insights into alphaherpesvirus virions (Beilstein et al., 2019; Bohannon et al., 2013; Laine et al., 2015), the primary application of recombinant viruses expressing fluorescent protein fusions is to monitor capsid transport in living cells (Diwaker and Wilson, 2019; Smith, 2012). 


\section{Navigating the cellular landscape}

Upon fusion-based entry at the plasma membrane, the PECC encounters cortical filamentous actin (F-actin) that impedes intracellular capsid trafficking (Jacob et al., 2015; Maurer et al., 2008). As already noted, Akt signaling initiated prior to entry may help dismantle this intrinsic hurdle to infection (Liu and Cohen, 2015; Nicola and Straus, 2004). In addition, actin depolymerization by cofilin, which was suppressed prior to entry, is now promoted (Zheng et al., 2014). Cofilin activation is driven by the pUS3 component of the PECC (Jacob et al., 2013). In the absence of pUS3, genome delivery to the nucleus is less efficient, but can be restored by depolymerizing F-actin with cytochalasin $D$ (Jacob et al., 2015). Thus, pUS3 is directly involved in breeching the cortical actin and allowing the capsid to gain deeper access to the cytoplasm (Figure 3). ROCK1 is also postulated to contribute to initial infection, but its precise role is unclear given that it inactivates cofilin (Frampton et al., 2010; Maekawa et al., 1999). Escape from the cortical actin also requires the microtubule plus-tip proteins: EB1, CLIP-170, and dynactin (Jovasevic et al., 2015). These proteins concentrate at the plus-ends of growing microtubules that typically reside at the cell periphery, and transient knock-down of any of these proteins restricts trafficking of the PECC. One explanation of this effect is that the plus-tip proteins may promote virus trafficking indirectly by maintaining proper cytoskeletal homeostasis. Alternatively, these cellular proteins may work together to capture the PECC and load it onto microtubules for subsequent retrograde transport by the cytoplasmic dynein microtubule motor, similar to endosome loading (Schuster et al., 2011). In support of the latter, the pUL36 component of the PECC associates with dynactin (Radtke et al., 2010; Zaichick et al., 2013). Given that depolymerization of actin by cytochalasin D rescues the escape of a US3-null virus from the cortical actin (Jacob et al., 2015), it would be interesting to determine whether the requirement of the plustip proteins would be reduced under this condition as well. More recently, Factin was demonstrated to compete with microtubules for EB1 (Alberico et al., 2016). This finding hints at further intricacy to the interplay between the virus particle, cortical actin, and microtubules. Possibly adding to this complexity, there are mixed reports regarding whether the proteasome may also 
participate in this initial step of infection. In one study, inhibition of the proteasome with MG132 caused viral particles to remain at the cell periphery following entry into cells (Delboy et al., 2008). The same group also reported that the HSV-1 E3 ubiquitin ligase, ICP0, works in tandem with proteasomes to facilitate trafficking from the periphery to the nucleus (Delboy and Nicola, 2011). However, the effect of MG132 could not be reproduced by another group (Sekine et al., 2017). Also of interest, local protein synthesis must occur upon PRV entry into axon terminals for retrograde axonal transport to ensue

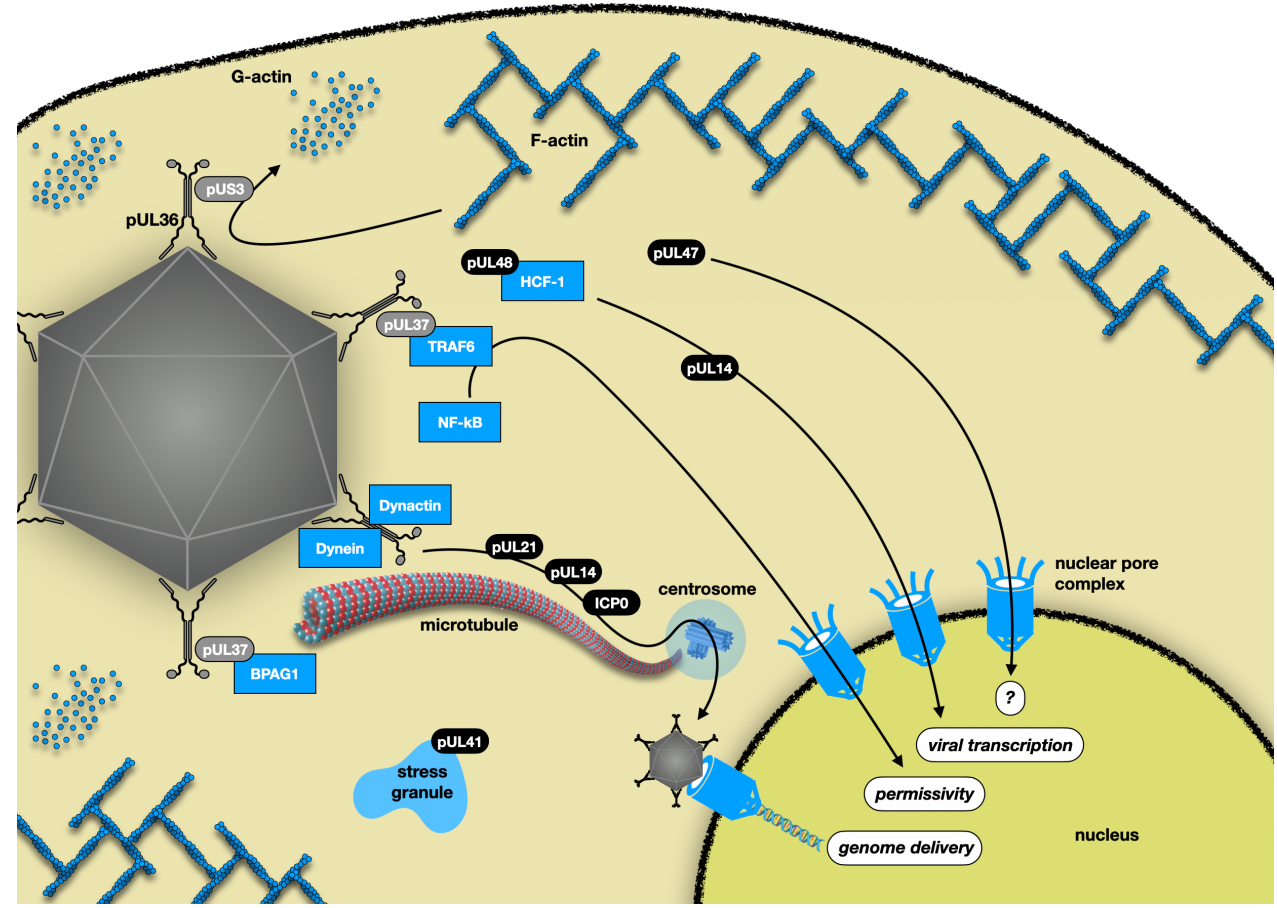

Figure 3. Post-entry events contributing to the delivery of viral genome to the cell nucleus. The post-entry capsid complex (consisting of the capsid, pUL36, pUL37, and pUS3) is shown in gray in the foreground at left. Tegument proteins that disassociate from the capsid are shown in black. Although the ICP0, pUL14 and pUL21 tegument proteins are shown apart from the capsid, their fates have not been reported and are therefore shown in black and gray. Cellular proteins are blue. Additional descriptions of viral effector functions are provided in Table 1. 
(Koyuncu et al., 2013b). One of the proteins synthesized upon infection is Lis1: a protein that can facilitate activation of dynein (Elshenawy et al., 2020; Htet et al., 2020; Marzo et al., 2020). Whether new protein synthesis is also needed in non-neuronal cells is unknown.

The PECC departs from the cell periphery by microtubule-based transport, and the microtubule depolymerizing drug, nocodazole, compromises this step of infection in non-polarized cells, polarized epithelia, and neurons (Kristensson et al., 1986b; Sodeik et al., 1997; Topp et al., 1996). Whereas microtubule transport is essential for infection of neurons via axons, it is dispensable in non-polarized cells although it substantially increases the rate of nuclear genome delivery (Richards et al., 2017; Sekine et al., 2017; Sodeik et al., 1997). Dynein is responsible for minus-end-directed microtubule-based transport in mammalian cells including retrograde axonal transport in neurons, whereas multiple kinesin family motors are responsible for plus-end-directed transport (Hirokawa and Noda, 2008; Reck-Peterson et al., 2018). Dynein inhibition also impairs trafficking of viral particles to nuclei in neurons and nonneuronal cells (Frampton et al., 2010; Jovasevic et al., 2015; Kristensson et al., 1986a). Close inspection of PECCs by transmission electron microscopy hints at dynein-like structures attached at capsid vertices, which is supported by immunogold detection (Sodeik et al., 1997). There is also indication that an opposing kinesin motor is present on the PECC. Inhibition of dynein-based transport results in accumulation of the particles at the cell periphery, which was interpreted as evidence of a kinesin motor (Dohner et al., 2002). In addition, time-lapse imaging of the PECC in neurons reveals a subtle bidirectionality to their movement with short-transient reversals in motion likely due to the presence of a kinesin motor (Smith et al., 2004). It is unknown whether a kinesin motor is of functional significance at this stage of infection or if the virus is actively suppressing a kinesin activity to afford preferential retrograde transport by dynein. The latter scenario may explain how alphaherpesviruses sustain retrograde transport over long distances, which is critical for their neuroinvasive phenotype. In contrast, adenoviruses, which are generally not neuroinvasive, also bind dynein and a kinesin but do not favor the 
activity of one motor over the other and use the motors to facilitate diffusion in the cytosol (Bremner et al., 2009; Gazzola et al., 2009; Suomalainen et al., 1999; Zhou et al., 2018). The ability of alphaherpesviruses to directly engage the microtubule transport machinery and sustain retrograde transport in axons also enables rapid genome delivery to the nucleus in non-neuronal cells (Richards et al., 2017). Although comparisons between viruses are challenging, there is a tentative indication that HSV-1 outpaces adenovirus genome delivery to the nucleus (Sekine et al., 2017). The PECC averages a speed of $1.2 \mathrm{microns} / \mathrm{s}$ and can sustain speeds in excess of $3 \mathrm{microns} / \mathrm{s}$ as it is transported towards the minus end of microtubules that are located at the centrosome (Smith et al., 2004).

The centrosome presents an interesting quandary for incoming viral particles. Because the minus-ends of microtubules reside at the centrosome, dynein cannot carry the PECC beyond this organelle, and capsids have been observed to transiently accumulate here on their way to the nucleus (Sodeik et al., 1997). Whereas adenoviruses use CRM1-dependent microtubule-based transport to reach the nucleus (Greber and Flatt, 2019; Strunze et al., 2005; Wang et al., 2017), this does not appear to be the case for HSV-1 (Sekine et al., 2017). Alphaherpesvirus transport from the centrosome to the nucleus was hypothesized to occur by a kinesin motor, but data supporting this model are not available. However, there is evidence that the cellular protein, dystonin/ BPAG1, contributes to this step of infection (McElwee et al., 2013). Dystonin/ BPAG1 is a member of the plakin family of proteins (Kunzli et al., 2016). There are three main isoforms of the protein with distinct patterns of expression: BPAG1a is expressed in multiple tissues including the brain, BPAG1b is expressed in muscle, and BPAG1e is expressed in epithelia. These proteins range in size from $300-800 \mathrm{kDa}$ and consist of a plakin domain and an assortment of additional domains that vary between isoforms. Dystonin/BPAG1 binds to dynactin and EB1, which accounts for its plus-tip distribution in cells, and supports retrograde axonal transport of endogenous cargoes in neurons (Kapur et al., 2014; Liu et al., 2003; Pasdeloup et al., 2013; Poliakova et al., 2014). These properties suggest that Dystonin/BPAG1 may promote transport 
of the PECC from the periphery to the centrosome. However, knock-down of dystonin/BPAG1 has only a modest effect on minus-end-directed microtubule transport to the centrosome and, instead, impedes subsequent transport from the centrosome to the nucleus (McElwee et al., 2013). Centrosome-to-nucleus trafficking is enigmatic, and the dystonin/BPAG phenotype provides an insight into this transport mechanism. Dystonin/BPAG may actively participate in the transport process or may serve as a release factor that frees the PECC from dynein upon arrival at the centrosome. Further insights into this mechanism will be aided by the findings that that pUL37 binds dystonin/BPAG1, and that pUL36 has a nuclear localization signal (NLS) that also contributes to this final transport step to the nucleus (Abaitua et al., 2012; Pasdeloup et al., 2013).

Capsids arriving at the nucleus preferentially bind to nuclear pore complexes (NPCs) (Anderson et al., 2014). The FG-repeat-containing nucleoporins that extend from the cytosolic surface of the NPC, Nup214 and Nup358/RanBP2, along with importin-beta, participate in capsid docking (Copeland et al., 2009; Ojala et al., 2000; Pasdeloup et al., 2009). Although importin-alphas function in a complex with importin-beta and bind to nuclear localization signals in substrate proteins, no individual importin-alpha has been identified as essential for capsid docking (Dohner et al., 2018). Either HSV-1 can use more than one importin-alpha or importin-alphas are not required during initial infection. HSV-1 capsids bind to Nup214, as does the pUL25 capsid protein of HSV-1 and PRV when transiently expressed; whether importin-beta or Nup358/RanBP2 participates in these interactions is not known (Pasdeloup et al., 2009). The role of pUL25's binding partner, pUL36, in the NPC interactions is also unclear. Antibodies reactive to pUL36 block capsid accumulation at the nuclear membrane when loaded into cells prior to infection, but this could be an indirect result of interfering with the role of pUL36 in capsid trafficking to nuclei (Copeland et al., 2009).

Although the role of pUL36 during capsid docking at NPCs requires further study, pUL36 is critical for the subsequent release of the viral genome from the capsid (Abaitua et al., 2011; Abaitua et al., 2009; Batterson et al., 1983; 
Roberts et al., 2009), as is pUL25 (Huffman et al., 2017; Preston et al., 2008; Rode et al., 2011). In contrast, pUL37 is dispensable for genome release into nuclei (Roberts et al., 2009). A proteolytic event is also necessary for genome release at NPCs and cleavage of pUL36 is coincident with this step, suggesting the role of pUL36 in genome release involves its processing (Jovasevic et al., 2008).

Alphaherpesvirus capsids orient at nuclear pore complexes such that a vertex faces into the pore (Granzow et al., 1997; Ojala et al., 2000). Given the similarities between the tailed bacteriophage and the herpesvirus capsid, it seems likely that the inward facing vertex is the portal, which would indicate that there are mechanisms at play to correctly orient the capsid and select for the portal vortex to face the NPC. Such an orientation may also be consistent with the high pressure within the capsid contributing to nuclear genome delivery by releasing the genome directly into the pore (Brandariz-Nunez et al., 2019), but no specific mechanism has yet been proposed. Following genome injection, the residual capsid shell remains intact and does not undergo any obvious morphological change (Granzow et al., 1997; Ojala et al., 2000). The empty capsid relic at the NPC is a testament to the stability of the alphaherpesvirus capsid shell, which may be an important factor to prevent detection of incoming viral DNA by nucleic acid sensors in the cytosol prior to arrival at the nucleus (Huffman et al., 2017).

\section{Viral effectors of genome delivery}

Investigations into the molecular mechanisms governing intracellular viral trafficking and nuclear genome delivery are complicated by the fact that the capsid and tegument proteins are structural elements of the virion, and their mutagenesis can, in some cases, prevent virion production. This is a significant technical dilemma. Although viruses lacking genes encoding essential proteins can be produced by trans-complementation, the presence of the transcomplemented protein in the virion precludes study of the deletion phenotype during initial infection. Many virion proteins that are non-essential for virus propagation in culture have been ruled out as essential for capsid trafficking to 
nuclei, including the pUS3 component of the PECC (Antinone et al., 2006). However, alphaherpesviruses cannot be produced in the absence of pUL36 (Desai, 2000; Smith and Enquist, 1999; Zhang et al., 2010) as well as the majority of the capsid proteins, and their study has required a more nuanced approach.

\section{Capsid}

Despite the grandiose assembly of the herpesvirus capsid, there is little evidence that it actively contributes to intracellular trafficking. VP26, which decorates the tips of hexons, is a compelling candidate for an effector protein during initial trafficking given its presence on the capsid surface at a high-copy number and its location away from pentons where it could otherwise be buried by tegument proteins (Figure 2). Yeast-2-hybrid studies identified dynein light chains as binding partners for VP26 (Douglas et al., 2004), which was unexpected given that dynein associates with the vertices of the PECC where VP26 is conspicuously absent (Sodeik et al., 1997). Nevertheless, tentative evidence that VP26 facilitates capsid transport was obtained by using a baculovirus expression system to assemble capsids with or without VP26, and then injecting the capsids into mammalian cells. The VP26-containing capsids tended to localize near the nucleus whereas capsids lacking VP26 remained dispersed throughout the cytoplasm (Douglas et al., 2004). However, follow up studies could not identify a role for VP26 in binding dynein to capsids (Wolfstein et al., 2006). Furthermore, viruses lacking VP26 engaged in dyneinbased transport indistinguishably from wild-type viruses (Antinone et al., 2006; Desai et al., 1998; Dohner et al., 2006). While these studies were completed over a decade ago, they bear witness to an important consideration when studying components of the PECC as potential effectors of intracellular transport: findings from reductionist models require confirmation in the context of infection.

The major capsid protein, VP5, is essential for virus propagation. While much of VP5 is buried within the capsid shell, the apical domain of the protein is exposed on the outer capsid surface where it could interact with cellular 
proteins. Mutations of the apical region of VP5 are not lethal but hinder capsid maturation late during infection. However, the apical mutant viruses have no measurable reduction in retrograde axonal transport, indicating that dynein recruitment is unperturbed (Ruhge et al., 2018).

The pUL25 protein is also of interest due to its exposure at vertices and because it adopts a unique conformation at the portal vertex (McElwee et al., 2018). A partial structure is available for HSV-1 pUL25 that reveals a box-like core with multiple exposed peptide loops (Bowman et al., 2006). Although pUL25 is essential for virus propagation (Klupp et al., 2006; Kuhn et al., 2008; McNab et al., 1998), a series of pUL25 mutants were produced based on the protein structure and found to impair genome encapsidation and nuclear egress during late infection (Cockrell et al., 2009; O'Hara et al., 2010). One exception was mutation of the HSV-1 pUL25 carboxyl terminus, which notably prevented release of the genome at the NPC (Huffman et al., 2017).

Beyond these targeted mutations, capsids isolated from infected cell nuclei, which are mostly devoid of tegument proteins, do not bind to dynein, kinesin-1, or kinesin-2. Capsid and tegument exposed from extracellular virions by detergent treatment are also incompetent for motor binding but, when extracted to remove the bulk of the tegument, the remaining capsid-tegument complexes bind all three motors and engage in microtubule transport in an in vitro assay (Radtke et al., 2010; Wolfstein et al., 2006). The pUL36 and pUL37 tegument proteins were considered candidates for this motor binding, and additional data supports that these proteins are effectors of PECC intracellular trafficking and genome delivery to nuclei.

\section{pUL36}

The pUL36 tegument protein is the largest protein encoded by the alphaherpesviruses, with a predicted molecular weight in excess of $300 \mathrm{kDa}$. The protein has a deubiquitinase (DUB) domain at the amino terminus and a capsid-binding domain (CBD) at the carboxy terminus (Coller et al., 2007; Kattenhorn et al., 2005). The domain organization of pUL36 can be simplified 
as DUB-linker-stalk-linker-CBD. The structures of two fragments of pUL36 have been determined. The first is the DUB from a non-neuroinvasive betaherpesvirus in complex with its ubiquitin substrate (Schlieker et al., 2007). The pUL36 DUB can be heterologously expressed by itself and has been adopted as a tool to keep proteins in a hypo-ubiquitinated state due to its potent activity (Stringer and Piper, 2011). During infection, the DUB is essential for transmission of PRV from epithelia to neurons in vivo but is dispensable for the delivery of genomes to nuclei of isolated epithelial and neuronal cells in culture; therefore, the DUB is not a core component of the genome delivery machinery (Huffmaster et al., 2015; Lee et al., 2009). The DUB is separated from the bulk of pUL36 by a divergent linker region that has one conserved motif embedded inside of it: a NLS (Abaitua and O'Hare, 2008). HSV-1 mutated in the pUL36 NLS are unable to propagate in culture yet produce fully formed extracellular viral particles (Abaitua et al., 2012). These particles enter cells but subsequently fail to traffic to nuclei and, instead, accumulate at the centrosome. Although more detailed studies are needed, these results indicate that dynein-based transport to the centrosome is not dependent on the NLS, whereas subsequent transport from the centrosome to the nucleus relies on it. This phenotype is reminiscent to wild-type HSV-1 infections in cells knockeddown for dystonin/BPAG1 (McElwee et al., 2013). Although pUL37 binds to dystonin/BPAG1 there is no indication of whether pUL36 does as well. The specific contributions of the pUL36 NLS and dystonin/BPAG1 to centrosometo-nucleus trafficking of the PECC will require further investigation.

The second structurally resolved region of pUL36 forms an elongated fiber that is predicted to be part of a larger helical region near the center of the protein (Scrima et al., 2015). This region was proposed to form a long coiled-coil stalk that could form from multiple copies of the protein. If pUL36 were a component of the portal tail, the full extent of such an elongated and flexible structure may not be easily identified by cryo-electron microscopy (McElwee et al., 2018; Schmid et al., 2012). The formation of an elongated structure could also explain why the protein is sensitive to sonication (Newcomb and Brown, 2010). 
In addition to full-length pUL36 that is anchored to capsid vertices, HSV-1 and PRV virions package naturally occurring truncated forms of pUL36 that lack the CBD (Michael et al., 2006; Radtke et al., 2010). These truncated forms of pUL36 are of unknown significance but presumably dissociate from the capsid upon entry into a cell. This could allow for the dispersal of the DUB and its access to a greater spectrum of host substrates. Unexpectedly, recombinant HSV-1 lacking the CBD of pUL36 remains competent to produce extracellular viral particles (Schipke et al., 2012). Upon entering a cell, the PECC loses the truncated pUL36 and fails to traffic to the nucleus. Thus, the retention of pUL36 on the capsid is essential because it mediates minus-end-directed microtubule transport by tethering dynein to the PECC (Zaichick et al., 2013). In fact, pUL36 interacts with dynein and dynactin in the absence of other viral proteins, and engages in robust microtubule-based transport when transiently expressed as a truncated form that lacks the carboxyl-terminal CBD. This finding has enabled studies of pUL36 function in a simplified system (Zaichick et al., 2013). Several observations made from this model require further study. Similar to capsids following entry, truncated pUL36 engages in processive microtubulebased transport, but unlike capsids this motion is highly bidirectional. As already discussed, the PECC may down-regulate an associated kinesin motor, which based on this latter observation appears to require viral proteins in addition to pUL36. These observations also indicate that the CBD may be autoinhibitory with regard to trafficking such that pUL36 expressed during infection may be inactive until the CBD is sequestered by binding to a capsid. In addition to these activities, capsid-retained pUL36 is also essential because it tethers pUL37 to the PECC (Daniel et al., 2018).

\section{pUL37}

Like pUL36, pUL37 supports PECC trafficking (Krautwald et al., 2009). Although there is currently no indication that pUL37 binds to microtubule motors, it modulates their activities (Richards et al., 2017). The amino-terminal half of pUL37 is formally dispensable for propagation in culture (Grzesik et al., 2019) but contains the region 2 (R2) effector that is necessary for full infectivity (Koenigsberg and Heldwein, 2017; Pitts et al., 2014). R2 sustains minus-end 
directed microtubule motion that is fundamental to retrograde axonal transport and the alphaherpesvirus neuroinvasive mechanism (Richards et al., 2017). When R2 is mutated, incoming HSV-1 and PRV display balanced plus- and minus-end-directed motion, reminiscent of the native state of adenovirus. Whereas R2 enhances trafficking to the cell nucleus in epithelial cells, R2 is essential for sustained long-distance trafficking to neuronal nuclei via axons. Thus, R2 mutant viruses are viable but are not neuroinvasive. The mechanism of action for R2 has not been determined but given that pUL37 binds dystonin/ BPAG1, which is necessary for centrosome-to-NPC transport, it seems reasonable to speculate that R2 may cooperate with dystonin/BPAG1 to mediate a switch to kinesin-based transport upon arriving at the centrosome. In this scenario, viruses mutated for R2 would be incapable of suppressing kinesin and thereby cause kinesin and dynein to compete with one another on the way to the centrosome. Because R2 mutants are non-neuroinvasive, they are compelling candidates as live-attenuated vaccines for veterinary and clinical alphaherpesviruses (Pickard et al., 2020; Richards et al., 2017).

The carboxyl-terminal half of pUL37 is a flexible elongated structure that is essential for viral propagation (Grzesik et al., 2019; Koenigsberg and Heldwein, 2018). This part of the protein binds pUL36 and also has deamidase activity (Bucks et al., 2011; Zhao et al., 2016). The latter antagonizes antiviral sensors but is dispensable for nuclear genome delivery during initial infection (Stults and Smith, 2019; Zhang et al., 2018; Zhao et al., 2016). As mentioned above, HSV-1 pUL37 has a TRAF6-binding motif in the carboxyl-terminal tail that activates NF-kB signaling (Liu et al., 2008). Both the deamidase and the TRAF6-binding site are absent from varicelloviruses, including PRV, indicating that these effectors are not part of the core genome delivery mechanism that is fundamental to the neuroinvasive phenotype of the alphaherpesviruses (Liu et al., 2008; Stults and Smith, 2019).

\section{Other tegument proteins}

In addition to pUL36 and pUL37, the pUS3 protein kinase is also a component of the PECC, but either it does not contribute to genome delivery or it is 
functionally redundant with another PECC component (Antinone et al., 2006; Coller and Smith, 2008; Olsen et al., 2006). The PECC may also contain additional tegument components that have yet to be identified either because reagents are not available for their study, or because their copy number in the PECC is below detection levels. For example, emissions from pUL13-GFP fusions are not easily detectable in extracellular PRV virions, precluding their use to examine the PECC (Coller and Smith, 2008). Whether tegument proteins that disassociate from the capsid upon entry contribute indirectly to PECC trafficking is yet to be seen.

The pUL14 tegument protein is tightly associated with capsids extracted from extracellular virions (Radtke et al., 2010), but is not established as a component of the PECC. HSV-1 lacking pUL14 propagates slowly but produces near wild-type levels of infections virus (Cunningham et al., 2000). The decreased rate of infection can be accounted for by defects in trafficking the PECC and the pUL48 tegument protein to the nucleus (Yamauchi et al., 2008). A screen for cellular binding partners of pUL14 did not identify proteins obviously involved in intracellular trafficking (Wu et al., 2011), which may indicate that pUL14 acts on viral proteins. Consistent with this possibility, pUL14 redistributes VP26 to the nucleus during transient co-expression (Yamauchi et al., 2001). However, VP26 does not appear to anchor tegument on assembled capsids based on cryo-electron microscopy reconstructions (Chen et al., 2001; Dai and Zhou, 2018; Zhou et al., 1999), making it unclear if the pUL14-VP26 interaction is relevant during initial infection. These observations do not rule out pUL14 as a PECC constituent; in fact, the finding that nuclear delivery of incoming HSV-1 lacking pUL14 cannot be rescued by expression of pUL14 in trans argues that the activity of pUL14 during initial infection may be conveyed as part of the PECC (Yamauchi et al., 2008).

The pUL21 tegument protein interacts with a dynein light chain (Yan et al., 2019), analogous to VP26 and several other viral proteins (Douglas et al., 2004). While the significance of this interaction is unclear, recombinant HSV-1 and HSV-2 lacking pUL21 infect cells with delayed kinetics due to a defect in 
early trafficking (Le Sage et al., 2013; Mbong et al., 2012). The null mutant also invades the nervous system of mice with delayed kinetics (Yan et al., 2019). Similarly, axonal infection of primary neurons in culture is delayed, but it is unknown whether the minus-end transport velocity and processivity are reduced or if transport following entry is initiated at reduced efficiency. As is the case for pUL14, pUL21 is tightly associated with capsids extracted from extracellular virions (Yan et al., 2019), but is not an established PECC component.

The pUL41 tegument protein is responsible for the virion-host shutoff activity. Its endoribonuclease activity degrades host mRNA and disrupts stress granules (Finnen et al., 2014; Finnen et al., 2016). Although pUL41 is dispensable in culture (Read and Frenkel, 1983; Strelow and Leib, 1995), its ability to rapidly antagonize translation and stress granule function upon entry likely supports its importance in vivo as a means to limit anti-viral responses (Onomoto et al., 2014). However, it is unclear if antiviral responses antagonize trafficking of the PECCs and the deliver genomes to nuclei in vivo.

ICPO (intracellular protein zero) is so named because it was not originally recognized as a structural component of virions. Nevertheless, ICPO is a lowcopy tegument protein (Yao and Courtney, 1992) that is tightly associated with capsids extracted from extracellular virions (Delboy et al., 2010; Maringer and Elliott, 2010). Although ICPO is not an established PECC component, the PECC of ICPO-null HSV-1 traffics to nuclei inefficiently, and ICPO was hypothesized to promote nuclear delivery by targeting a cellular or a viral protein for degradation by virtue of its E3 ubiquitin ligase activity (Delboy and Nicola, 2011). More recently, ICPO was reported to down regulate autophagy early during infection (Waisner and Kalamvoki, 2019). The 3-hour time point examined in these experiments is too late to conclude whether virion-delivered, or de novo expressed, ICPO was responsible for the effect on autophagy. If virion-delivered ICPO antagonizes autophagy, this could account for the nuclear trafficking defect seen with the null virus. 
Each of the proteins discussed above requires further study to delineate their specific contributions to initial infection, as do other tegument proteins that have yet to be examined in this context. A summary of the contributions of tegument proteins during initial infection is presented in Table 1.

\section{Conclusions and outlook}

Delivery of viral genomes to the nucleus is not a trivial problem, especially for the alphaherpesviruses, which accomplish this in two cell types with distinct polarized architectures: epithelial cells and neurons. There are multiple obstacles that these viruses overcome to traffic to nuclei including escaping the cortical actin network upon entering cells, loading onto microtubules, suppressing kinesin motors in favor of sustaining dynein-based transport to the centrosome, trafficking from the centrosome to the nucleus, docking at nuclear pore complexes, and releasing the genome into the nucleus. The specific tactics used by these viruses to overcome these obstacles contribute to their broader neuroinvasive phenotype. The complexity of the tegument provides for a rich assortment of viral effector proteins that enter the cytosol upon entry and rapidly increase the permissivity of a cell to infection. Of these, pUL36 and pUL37 remain associated with the incoming capsid and are essential for its trafficking. How these proteins function is beginning to be delineated, but our working understanding of their contributions to initial infection is rudimentary. There are many exciting questions remaining to be addressed, and likely many more that have yet to be realized. A full accounting of PECC components is needed and, ultimately, a molecular understanding of the contributions of each component to initial infection. An understanding of the alphaherpesvirus genome delivery mechanism will not only advance the fields of virology, neuroscience, and cell biology but also provide a foundation for next generation gene delivery vectors, trans-synaptic tracers, oncolytic vectors, and vaccines. 
Table 1. Activities of virion-delivered tegument proteins during initial infection. Tegument proteins are multi-functional proteins that have roles throughout the infectious cycle, as well as serving as structural components of virions. In many instances, studies do not specifically examine the effects of these proteins during initial infection, prior to their de novo expression. The information summarizes the reported functions of individual tegument proteins during initial infection. The listed functions are not necessarily dependent on the indicated enzymatic activities (see text). Protein names are based on HSV/PRV nomenclature.

\begin{tabular}{|c|c|c|c|c|}
\hline & $\begin{array}{l}\text { Enzymatic } \\
\text { activity }\end{array}$ & $\begin{array}{l}\text { Capsid } \\
\text { retained }\end{array}$ & Functions that are reported or implicated during ingress & Reference \\
\hline pUL7 & - & ? & & \\
\hline PUL13 & Protein kinase & ? & Promotes tegument disassembly by phosphorylating VP22. & Morrison 1998a \\
\hline pUL14 & - & ? & Promotes nuclear trafficking of capsids and pUL48 by unknown mechanisms. & Yamauchi 2008 \\
\hline pUL16 & - & - & Promotes tegument disassembly by detaching from the capsid. & Meckes 2008 \\
\hline pUL21 & - & ? & $\begin{array}{l}\text { Enhances infection of neurons via retrograde axonal transport, possibly by binding to } \\
\text { a dynein light chain. }\end{array}$ & Yan 2019 \\
\hline pUL36 (VP1/2) & Deubiquitinase & + & $\begin{array}{l}\text { Retains pUL } 37 \text { and pUS3 on the capsid. Recruits dynein microtubule motor to } \\
\text { promote capsid trafficking to the centrosome. NLS supports capsid transport from } \\
\text { centrosome to nucleus. Cleavage is coincident with genome release from the capsid. }\end{array}$ & $\begin{array}{l}\text { Jovasevic } 2008 \\
\text { Abaitua } 2012 \\
\text { Zaichick } 2013 \\
\text { Daniel } 2018\end{array}$ \\
\hline pUL37 & Deamidase & + & $\begin{array}{l}\text { Sustains dynein-based microtubule transport by suppressing opposing transport. } \\
\text { Binds dystonin/BPAG1, which enhances capsid transport from centrosome to } \\
\text { nucleus. Activates NF-kB signaling. }\end{array}$ & $\begin{array}{l}\text { Liu } 2008 \\
\text { McElwee } 2013 \\
\text { Richards } 2017\end{array}$ \\
\hline pUL41 (VHS) & Endoribonuclease & ? & Disrupts pre-existing stress granules and antagonizes translation of host mRNA. & $\begin{array}{l}\text { Kwong } 1988 \\
\text { Finnen } 2014,2016\end{array}$ \\
\hline pUL46 (VP11/12) & - & - & ? & \\
\hline pUL47 (VP13/14) & - & - & Traffics into nucleus, but significance unknown. & Morrison 1998b \\
\hline pUL48 (VP16) & - & - & Binds host HCF-1 protein to import into nucleus and promote viral gene expression. & La Boissiere 1999 \\
\hline pUL49 (VP22) & - & - & ? & \\
\hline pUL50 & dUTPase & ? & & \\
\hline pUS3 & Protein kinase & + & Disassembles filamentous actin to promote capsid trafficking to nucleus. & Jacob 2015 \\
\hline ICPO & E3 ubiquitin ligase & ? & $\begin{array}{l}\text { Promotes nuclear trafficking of capsids possibly by targeting anti-viral host proteins } \\
\text { for proteasomal degradation. }\end{array}$ & Delboy 2011 \\
\hline ICP4 & - & ? & ? & \\
\hline
\end{tabular}

\section{References}

Abaitua, F., Daikoku, T., Crump, C.M., Bolstad, M., and O'Hare, P. (2011). A single mutation responsible for temperature-sensitive entry and assembly defects in the VP1-2 protein of herpes simplex virus. J Virol 85, 2024-2036.

Abaitua, F., Hollinshead, M., Bolstad, M., Crump, C.M., and O'Hare, P. (2012). A nuclear localization signal in herpesvirus protein VP1-2 is essential for infection via capsid routing to the nuclear pore. J Virol 86, 8998-9014.

Abaitua, F., and O'Hare, P. (2008). Identification of a highly conserved, functional nuclear localization signal within the $\mathrm{N}$-terminal region of herpes simplex virus type 1 VP1-2 tegument protein. J Virol 82, 5234-5244. 
Abaitua, F., Souto, R.N., Browne, H., Daikoku, T., and O'Hare, P. (2009). Characterization of the herpes simplex virus (HSV)-1 tegument protein VP1-2 during infection with the HSV temperature-sensitive mutant tsB7. J Gen Virol 90, 2353-2363.

Ace, C.I., McKee, T.A., Ryan, J.M., Cameron, J.M., and Preston, C.M. (1989). Construction and characterization of a herpes simplex virus type 1 mutant unable to transinduce immediate-early gene expression. J Virol 63, 2260-2269.

Aggarwal, A., Miranda-Saksena, M., Boadle, R.A., Kelly, B.J., Diefenbach, R.J., Alam, W., and Cunningham, A.L. (2012). Ultrastructural visualization of individual tegument protein dissociation during entry of herpes simplex virus 1 into human and rat dorsal root ganglion neurons. J Virol 86, 6123-6137.

Alberico, E.O., Zhu, Z.C., Wu, Y.O., Gardner, M.K., Kovar, D.R., and Goodson, H.V. (2016). Interactions between the Microtubule Binding Protein EB1 and F-Actin. J Mol Biol 428, 1304-1314.

Anderson, F., Savulescu, A.F., Rudolph, K., Schipke, J., Cohen, I., Ibiricu, I., Rotem, A., Grunewald, K., Sodeik, B., and Harel, A. (2014). Targeting of viral capsids to nuclear pores in a cell-free reconstitution system. Traffic 15, 1266-1281.

Antinone, S.E., Shubeita, G.T., Coller, K.E., Lee, J.I., Haverlock-Moyns, S., Gross, S.P., and Smith, G.A. (2006). The Herpesvirus capsid surface protein, VP26, and the majority of the tegument proteins are dispensable for capsid transport toward the nucleus. J Virol 80, 5494-5498.

Antinone, S.E., and Smith, G.A. (2006). Two modes of herpesvirus trafficking in neurons: membrane acquisition directs motion. J Virol 80, 11235-11240.

Antinone, S.E., and Smith, G.A. (2010). Retrograde axon transport of herpes simplex virus and pseudorabies virus: a live-cell comparative analysis. J Virol 84, 1504-1512.

Baker, M.L., Jiang, W., Rixon, F.J., and Chiu, W. (2005). Common ancestry of herpesviruses and tailed DNA bacteriophages. J Virol 79, 14967-14970.

Batterson, W., Furlong, D., and Roizman, B. (1983). Molecular genetics of herpes simplex virus. VIII. further characterization of a temperature-sensitive 
mutant defective in release of viral DNA and in other stages of the viral reproductive cycle. J Virol 45, 397-407.

Batterson, W., and Roizman, B. (1983). Characterization of the herpes simplex virion-associated factor responsible for the induction of alpha genes. J Virol 46, 371-377.

Bauer, D.W., Huffman, J.B., Homa, F.L., and Evilevitch, A. (2013). Herpes virus genome, the pressure is on. J Am Chem Soc 135, 11216-11221.

Beilstein, F., Cohen, G.H., Eisenberg, R.J., Nicolas, V., Esclatine, A., and Pasdeloup, D. (2019). Dynamic organization of Herpesvirus glycoproteins on the viral envelope revealed by super-resolution microscopy. PLoS Pathog 15 , e1008209.

Bohannon, K.P., Jun, Y., Gross, S.P., and Smith, G.A. (2013). Differential protein partitioning within the herpesvirus tegument and envelope underlies a complex and variable virion architecture. Proc Natl Acad Sci U S A 110, E1613-1620.

Bohannon, K.P., Sollars, P.J., Pickard, G.E., and Smith, G.A. (2012). Fusion of a fluorescent protein to the pUL25 minor capsid protein of pseudorabies virus allows live-cell capsid imaging with negligible impact on infection. J Gen Virol 93, 124-129.

Borza, C.M., and Hutt-Fletcher, L.M. (2002). Alternate replication in B cells and epithelial cells switches tropism of Epstein-Barr virus. Nat Med 8, 594-599.

Böttcher, S., Klupp, B.G., Granzow, H., Fuchs, W., Michael, K., and Mettenleiter, T.C. (2006). Identification of a 709-amino-acid internal nonessential region within the essential conserved tegument protein (p)UL36 of pseudorabies virus. J Virol 80, 9910-9915.

Bowman, B.R., Welschhans, R.L., Jayaram, H., Stow, N.D., Preston, V.G., and Quiocho, F.A. (2006). Structural characterization of the UL25 DNA-packaging protein from herpes simplex virus type 1. J Virol 80, 2309-2317.

Brandariz-Nunez, A., Liu, T., Du, T., and Evilevitch, A. (2019). Pressure-driven release of viral genome into a host nucleus is a mechanism leading to herpes infection. Elife 8. 
Bremner, K.H., Scherer, J., Yi, J., Vershinin, M., Gross, S.P., and Vallee, R.B. (2009). Adenovirus transport via direct interaction of cytoplasmic dynein with the viral capsid hexon subunit. Cell Host Microbe 6, 523-535.

Bucks, M.A., Murphy, M.A., O'Regan, K.J., and Courtney, R.J. (2011). Identification of interaction domains within the UL37 tegument protein of herpes simplex virus type 1. Virology 416, 42-53.

Cardone, G., Newcomb, W.W., Cheng, N., Wingfield, P.T., Trus, B.L., Brown, J.C., and Steven, A.C. (2012). The UL36 tegument protein of herpes simplex virus 1 has a composite binding site at the capsid vertices. J Virol 86, 4058-4064.

Cardone, G., Winkler, D.C., Trus, B.L., Cheng, N., Heuser, J.E., Newcomb, W.W., Brown, J.C., and Steven, A.C. (2007). Visualization of the herpes simplex virus portal in situ by cryo-electron tomography. Virology 361, 426-434.

Chen, D.H., Jakana, J., McNab, D., Mitchell, J., Zhou, Z.H., Dougherty, M., Chiu, W., and Rixon, F.J. (2001). The pattern of tegument-capsid interaction in the herpes simplex virus type 1 virion is not influenced by the small hexonassociated protein VP26. J Virol 75, 11863-11867.

Chen, J.J., Zhu, Z., Gershon, A.A., and Gershon, M.D. (2004). Mannose 6phosphate receptor dependence of varicella zoster virus infection in vitro and in the epidermis during varicella and zoster. Cell 119, 915-926.

Cheshenko, N., Trepanier, J.B., Stefanidou, M., Buckley, N., Gonzalez, P., Jacobs, W., and Herold, B.C. (2013). HSV activates Akt to trigger calcium release and promote viral entry: novel candidate target for treatment and suppression. FASEB J 27, 2584-2599.

Cockrell, S.K., Sanchez, M.E., Erazo, A., and Homa, F.L. (2009). Role of the UL25 protein in herpes simplex virus DNA encapsidation. J Virol 83, 47-57.

Coller, K.E., Lee, J.I., Ueda, A., and Smith, G.A. (2007). The capsid and tegument of the alpha herpesviruses are linked by an interaction between the UL25 and VP1/2 proteins. J Virol 81, 11790-11797.

Coller, K.E., and Smith, G.A. (2008). Two viral kinases are required for sustained long distance axon transport of a neuroinvasive herpesvirus. Traffic 9, 1458-1470. 
Conway, J.F., Cockrell, S.K., Copeland, A.M., Newcomb, W.W., Brown, J.C., and Homa, F.L. (2010). Labeling and localization of the herpes simplex virus capsid protein UL25 and its interaction with the two triplexes closest to the penton. J Mol Biol 397, 575-586.

Copeland, A.M., Newcomb, W.W., and Brown, J.C. (2009). Herpes simplex virus replication: roles of viral proteins and nucleoporins in capsid-nucleus attachment. J Virol 83, 1660-1668.

Cunningham, C., Davison, A.J., MacLean, A.R., Taus, N.S., and Baines, J.D. (2000). Herpes simplex virus type 1 gene UL14: phenotype of a null mutant and identification of the encoded protein. J Virol 74, 33-41.

Curtis, R., Adryan, K.M., Zhu, Y., Harkness, P.J., Lindsay, R.M., and DiStefano, P.S. (1993). Retrograde axonal transport of ciliary neurotrophic factor is increased by peripheral nerve injury. Nature 365, 253-255.

Dai, X., and Zhou, Z.H. (2018). Structure of the herpes simplex virus 1 capsid with associated tegument protein complexes. Science 360, eaao7298.

Daniel, G.R., Pegg, C.E., and Smith, G.A. (2018). Dissecting the herpesvirus architecture by targeted proteolysis. J Virol 92, e00738-00718.

de Wind, N., Wagenaar, F., Pol, J., Kimman, T., and Berns, A. (1992). The pseudorabies virus homology of the herpes simplex virus UL21 gene product is a capsid protein which is involved in capsid maturation. J Virol 66, 7096-7103.

Dedeo, C.L., Cingolani, G., and Teschke, C.M. (2019). Portal Protein: The Orchestrator of Capsid Assembly for the dsDNA Tailed Bacteriophages and Herpesviruses. Annu Rev Virol 6, 141-160.

Delboy, M.G., and Nicola, A.V. (2011). A pre-immediate-early role for tegument ICP0 in the proteasome-dependent entry of herpes simplex virus. J Virol 85, 5910-5918.

Delboy, M.G., Roller, D.G., and Nicola, A.V. (2008). Cellular proteasome activity facilitates herpes simplex virus entry at a postpenetration step. J Virol 82, 3381-3390.

Delboy, M.G., Siekavizza-Robles, C.R., and Nicola, A.V. (2010). Herpes simplex virus tegument ICPO is capsid associated, and its E3 ubiquitin ligase domain is important for incorporation into virions. J Virol 84, 1637-1640. 
Desai, P., DeLuca, N.A., and Person, S. (1998). Herpes simplex virus type 1 VP26 is not essential for replication in cell culture but influences production of infectious virus in the nervous system of infected mice. Virology 247, 115-124.

Desai, P., and Person, S. (1998). Incorporation of the green fluorescent protein into the herpes simplex virus type 1 capsid. J Virol 72, 7563-7568.

Desai, P.J. (2000). A null mutation in the UL36 gene of herpes simplex virus type 1 results in accumulation of unenveloped DNA-filled capsids in the cytoplasm of infected cells. J Virol 74, 11608-11618.

Devadas, D., Koithan, T., Diestel, R., Prank, U., Sodeik, B., and Dohner, K. (2014). Herpes simplex virus internalization into epithelial cells requires $\mathrm{Na}+$ / $\mathrm{H}+$ exchangers and $\mathrm{p} 21$-activated kinases but neither clathrin- nor caveolinmediated endocytosis. J Virol 88, 13378-13395.

Diwaker, D., and Wilson, D.W. (2019). Microtubule-Dependent Trafficking of Alphaherpesviruses in the Nervous System: The Ins and Outs. Viruses 11.

Dohner, K., Radtke, K., Schmidt, S., and Sodeik, B. (2006). Eclipse phase of herpes simplex virus type 1 infection: Efficient dynein-mediated capsid transport without the small capsid protein VP26. J Virol 80, 8211-8224.

Dohner, K., Ramos-Nascimento, A., Bialy, D., Anderson, F., Hickford-Martinez, A., Rother, F., Koithan, T., Rudolph, K., Buch, A., Prank, U., et al. (2018). Importin alpha1 is required for nuclear import of herpes simplex virus proteins and capsid assembly in fibroblasts and neurons. PLoS Pathog 14, e1006823.

Dohner, K., Wolfstein, A., Prank, U., Echeverri, C., Dujardin, D., Vallee, R., and Sodeik, B. (2002). Function of Dynein and dynactin in herpes simplex virus capsid transport. Mol Biol Cell 13, 2795-2809.

Douglas, M.W., Diefenbach, R.J., Homa, F.L., Miranda-Saksena, M., Rixon, F.J., Vittone, V., Byth, K., and Cunningham, A.L. (2004). Herpes simplex virus type 1 capsid protein VP26 interacts with dynein light chains RP3 and Tctex1 and plays a role in retrograde cellular transport. J Biol Chem 279, 28522-28530.

Duda, R.L., Hendrix, R.W., Huang, W.M., and Conway, J.F. (2006). Shared architecture of bacteriophage SPO1 and herpesvirus capsids. Curr Biol 16, R11-13. 
El Kasmi, I., and Lippe, R. (2014). HSV-1 gN partners with gM to modulate the viral fusion machinery. J Virol 89, 2313-2323.

Elshenawy, M.M., Kusakci, E., Volz, S., Baumbach, J., Bullock, S.L., and Yildiz, A. (2020). Lis1 activates dynein motility by modulating its pairing with dynactin. Nat Cell Biol 22, 570-578.

Fan, W.H., Roberts, A.P., McElwee, M., Bhella, D., Rixon, F.J., and Lauder, R. (2014). The Large Tegument Protein pUL36 is Essential for Formation of the Capsid Vertex Specific Component at the Capsid-Tegument Interface of HSV-1. J Virol 89, 1502-1511.

Fenwick, M.L., and Walker, M.J. (1978). Suppression of the synthesis of cellular macromolecules by herpes simplex virus. J Gen Virol 41, 37-51.

Finnen, R.L., Hay, T.J., Dauber, B., Smiley, J.R., and Banfield, B.W. (2014). The herpes simplex virus 2 virion-associated ribonuclease vhs interferes with stress granule formation. J Virol 88, 12727-12739.

Finnen, R.L., Zhu, M., Li, J., Romo, D., and Banfield, B.W. (2016). Herpes Simplex Virus 2 Virion Host Shutoff Endoribonuclease Activity Is Required To Disrupt Stress Granule Formation. J Virol 90, 7943-7955.

Frame, M.C., Purves, F.C., McGeoch, D.J., Marsden, H.S., and Leader, D.P. (1987). Identification of the herpes simplex virus protein kinase as the product of viral gene US3. J Gen Virol 68 ( Pt 10), 2699-2704.

Frampton, A.R., Jr., Stolz, D.B., Uchida, H., Goins, W.F., Cohen, J.B., and Glorioso, J.C. (2007). Equine herpesvirus 1 enters cells by two different pathways, and infection requires the activation of the cellular kinase ROCK1. J Virol 81, 10879-10889.

Frampton, A.R., Jr., Uchida, H., von Einem, J., Goins, W.F., Grandi, P., Cohen, J.B., Osterrieder, N., and Glorioso, J.C. (2010). Equine herpesvirus type 1 (EHV-1) utilizes microtubules, dynein, and ROCK1 to productively infect cells. Vet Microbiol 141, 12-21.

Frank, I., and Friedman, H.M. (1989). A novel function of the herpes simplex virus type 1 FC receptor: participation in bipolar bridging of antiviral immunoglobulin G. J Virol 63, 4479-4488. 
Fuchs, W., Granzow, H., Klupp, B.G., Kopp, M., and Mettenleiter, T.C. (2002). The UL48 tegument protein of pseudorabies virus is critical for intracytoplasmic assembly of infectious virions. J Virol 76, 6729-6742.

Fuchs, W., Klupp, B.G., Granzow, H., and Mettenleiter, T.C. (2004). Essential function of the pseudorabies virus UL36 gene product is independent of its interaction with the UL37 protein. J Virol 78, 11879-11889.

Fuller, A.O., Santos, R.E., and Spear, P.G. (1989). Neutralizing antibodies specific for glycoprotein $\mathrm{H}$ of herpes simplex virus permit viral attachment to cells but prevent penetration. J Virol 63, 3435-3443.

Gazzola, M., Burckhardt, C.J., Bayati, B., Engelke, M., Greber, U.F., and Koumoutsakos, P. (2009). A stochastic model for microtubule motors describes the in vivo cytoplasmic transport of human adenovirus. PLoS Comput Biol 5, e1000623.

Gluska, S., Zahavi, E.E., Chein, M., Gradus, T., Bauer, A., Finke, S., and Perlson, E. (2014). Rabies Virus Hijacks and accelerates the p75NTR retrograde axonal transport machinery. PLoS Pathog 10, e1004348.

Granzow, H., Klupp, B.G., and Mettenleiter, T.C. (2005). Entry of pseudorabies virus: an immunogold-labeling study. J Virol 79, 3200-3205.

Granzow, H., Weiland, F., Jons, A., Klupp, B.G., Karger, A., and Mettenleiter, T.C. (1997). Ultrastructural analysis of the replication cycle of pseudorabies virus in cell culture: a reassessment. J Virol 71, 2072-2082.

Greber, U.F., and Flatt, J.W. (2019). Adenovirus Entry: From Infection to Immunity. Annu Rev Virol 6, 177-197.

Gromeier, M., and Wimmer, E. (1998). Mechanism of injury-provoked poliomyelitis. J Virol 72, 5056-5060.

Grunewald, K., Desai, P., Winkler, D.C., Heymann, J.B., Belnap, D.M., Baumeister, W., and Steven, A.C. (2003). Three-dimensional structure of herpes simplex virus from cryo-electron tomography. Science 302, 1396-1398.

Grzesik, P., Pryce, E.N., Bhalala, A., Vij, M., Ahmed, R., Etienne, L., Perez, P., McCaffery, J.M., and Desai, A.P.J. (2019). Functional Domains of the Herpes Simplex Virus Type 1 Tegument Protein pUL37: The Amino Terminus is Dispensable for Virus Replication in Tissue Culture. Viruses 11. 
Hanz, S., Perlson, E., Willis, D., Zheng, J.Q., Massarwa, R., Huerta, J.J., Koltzenburg, M., Kohler, M., van-Minnen, J., Twiss, J.L., et al. (2003). Axoplasmic importins enable retrograde injury signaling in lesioned nerve. Neuron 40, 1095-1104.

Heming, J.D., Huffman, J.B., Jones, L.M., and Homa, F.L. (2014). Isolation and characterization of the herpes simplex virus 1 terminase complex. J Virol 88, 225-236.

Hirokawa, N., and Noda, Y. (2008). Intracellular transport and kinesin superfamily proteins, KIFs: structure, function, and dynamics. Physiol Rev 88, 1089-1118.

Hogue, I.B., Jean, J., Esteves, A.D., Tanneti, N.S., Scherer, J., and Enquist, L.W. (2018). Functional Carboxy-Terminal Fluorescent Protein Fusion to Pseudorabies Virus Small Capsid Protein VP26. J Virol 92.

Hook, L.M., Huang, J., Jiang, M., Hodinka, R., and Friedman, H.M. (2008). Blocking antibody access to neutralizing domains on glycoproteins involved in entry as a novel mechanism of immune evasion by herpes simplex virus type 1 glycoproteins $C$ and E. J Virol 82, 6935-6941.

Hoppe, S., Schelhaas, M., Jaeger, V., Liebig, T., Petermann, P., and KnebelMorsdorf, D. (2006). Early herpes simplex virus type 1 infection is dependent on regulated Rac1/Cdc42 signalling in epithelial MDCKII cells. J Gen Virol 87, 3483-3494.

Htet, Z.M., Gillies, J.P., Baker, R.W., Leschziner, A.E., DeSantis, M.E., and Reck-Peterson, S.L. (2020). LIS1 promotes the formation of activated cytoplasmic dynein-1 complexes. Nat Cell Biol 22, 518-525.

Huet, A., Makhov, A.M., Huffman, J.B., Vos, M., Homa, F.L., and Conway, J.F. (2016). Extensive subunit contacts underpin herpesvirus capsid stability and interior-to-exterior allostery. Nature structural and molecular biology.

Huffman, J.B., Daniel, G.R., Falck-Pedersen, E., Huet, A., Smith, G.A., Conway, J.F., and Homa, F.L. (2017). The C-terminus of the herpes simplex virus pUL25 protein is required for release of viral genomes from capsids bound to nuclear pores. J Virol 91. 
Huffmaster, N.J., Sollars, P.J., Richards, A.L., Pickard, G.E., and Smith, G.A. (2015). Dynamic ubiquitination drives herpesvirus neuroinvasion. Proc Natl Acad Sci U S A 112, 12818-12823.

Jacob, T., Van den Broeke, C., Grauwet, K., Baert, K., Claessen, C., De Pelsmaeker, S., Van Waesberghe, C., and Favoreel, H.W. (2015). Pseudorabies virus US3 leads to filamentous actin disassembly and contributes to viral genome delivery to the nucleus. Vet Microbiol 177, 379-385.

Jacob, T., Van den Broeke, C., van Troys, M., Waterschoot, D., Ampe, C., and Favoreel, H.W. (2013). Alphaherpesviral US3 kinase induces cofilin dephosphorylation to reorganize the actin cytoskeleton. J Virol 87, 4121-4126.

Jovasevic, V., Liang, L., and Roizman, B. (2008). Proteolytic cleavage of VP1-2 is required for release of herpes simplex virus 1 DNA into the nucleus. J Virol 82, 3311-3319.

Jovasevic, V., Naghavi, M.H., and Walsh, D. (2015). Microtubule plus endassociated CLIP-170 initiates HSV-1 retrograde transport in primary human cells. J Cell Biol 211, 323-337.

Kapur, M., Maloney, M.T., Wang, W., Chen, X., Millan, I., Mooney, T., Yang, J., and Yang, Y. (2014). A SxIP motif interaction at the microtubule plus end is important for processive retrograde axonal transport. Cell Mol Life Sci 71, 4043-4054.

Kattenhorn, L.M., Korbel, G.A., Kessler, B.M., Spooner, E., and Ploegh, H.L. (2005). A deubiquitinating enzyme encoded by HSV-1 belongs to a family of cysteine proteases that is conserved across the family Herpesviridae. Mol Cell 19, 547-557.

Klupp, B.G., Fuchs, W., Granzow, H., Nixdorf, R., and Mettenleiter, T.C. (2002). Pseudorabies Virus UL36 Tegument Protein Physically Interacts with the UL37 Protein. J Virol 76, 3065-3071.

Klupp, B.G., Granzow, H., Keil, G.M., and Mettenleiter, T.C. (2006). The capsidassociated UL25 protein of the alphaherpesvirus pseudorabies virus is nonessential for cleavage and encapsidation of genomic DNA but is required for nuclear egress of capsids. J Virol 80, 6235-6246. 
Ko, D.H., Cunningham, A.L., and Diefenbach, R.J. (2010). The major determinant for addition of tegument protein pUL48 (VP16) to capsids in herpes simplex virus type 1 is the presence of the major tegument protein pUL36 (VP1/2). J Virol 84, 1397-1405.

Koenigsberg, A.L., and Heldwein, E. (2018). The dynamic nature of the conserved tegument protein UL37 of herpesviruses. J Biol Chem 293, 15827-15839.

Koenigsberg, A.L., and Heldwein, E.E. (2017). Crystal structure of the Nterminal half of the traffic controller UL37 from Herpes Simplex virus Type 1. J Virol 91, e01244-01217.

Komala Sari, T., Gianopulos, K.A., and Nicola, A.V. (2020a). Glycoprotein C of Herpes Simplex Virus 1 Shields Glycoprotein B from Antibody Neutralization. J Virol 94.

Komala Sari, T., Gianopulos, K.A., Weed, D.J., Schneider, S.M., Pritchard, S.M., and Nicola, A.V. (2020b). Herpes Simplex Virus Glycoprotein C Regulates Low-pH Entry. mSphere 5.

Kornfeind, E.M., and Visalli, R.J. (2018). Human herpesvirus portal proteins: Structure, function, and antiviral prospects. Rev Med Virol 28, e1972.

Koyuncu, O.O., Hogue, I.B., and Enquist, L.W. (2013a). Virus infections in the nervous system. Cell Host Microbe 13, 379-393.

Koyuncu, O.O., Perlman, D.H., and Enquist, L.W. (2013b). Efficient retrograde transport of pseudorabies virus within neurons requires local protein synthesis in axons. Cell Host Microbe 13, 54-66.

Kramer, T., Greco, T.M., Enquist, L.W., and Cristea, I.M. (2011). Proteomic characterization of pseudorabies virus extracellular virions. J Virol 85, 6427-6441.

Krautwald, M., Fuchs, W., Klupp, B.G., and Mettenleiter, T.C. (2009). Translocation of incoming pseudorabies virus capsids to the cell nucleus is delayed in the absence of tegument protein pUL37. J Virol 83, 3389-3396.

Krautwald, M., Maresch, C., Klupp, B.G., Fuchs, W., and Mettenleiter, T.C. (2008). Deletion or green fluorescent protein tagging of the pUL35 capsid component of pseudorabies virus impairs virus replication in cell culture and neuroinvasion in mice. J Gen Virol 89, 1346-1351. 
Kristensson, K., Lycke, E., Röyttä, M., Svennerholm, B., and Vahlne, A. (1986a). Neuritic transport of herpes simplex virus in rat sensory neurons in vitro. Effects of substances interacting with microtubular function and axonal flow [nocodazole, taxol and erythro-9-3-(2-hydroxynonyl)adenine]. J Gen Virol 67, 2023-2028.

Kristensson, K., Lycke, E., Röyttä, M., Svennerholm, B., and Vahlne, A. (1986b). Neuritic transport of herpes simplex virus in rat sensory neurons in vitro. Effects of substances interacting with microtubular function and axonal flow [nocodazole, taxol and erythro-9-3-(2-hydroxynonyl)adenine]. J Gen Virol 67, 2023-2028.

Krupovic, M., and Koonin, E.V. (2017). Multiple origins of viral capsid proteins from cellular ancestors. Proc Natl Acad Sci U S A 114, E2401-E2410.

Kuhn, J., Leege, T., Klupp, B.G., Granzow, H., Fuchs, W., and Mettenleiter, T.C. (2008). Partial functional complementation of a pseudorabies virus UL25 deletion mutant by herpes simplex virus type 1 pUL25 indicates overlapping functions of alphaherpesvirus pUL25 proteins. J Virol 82, 5725-5734.

Kunzli, K., Favre, B., Chofflon, M., and Borradori, L. (2016). One gene but different proteins and diseases: the complexity of dystonin and bullous pemphigoid antigen 1. Exp Dermatol 25, 10-16.

Laine, R.F., Albecka, A., van de Linde, S., Rees, E.J., Crump, C.M., and Kaminski, C.F. (2015). Structural analysis of herpes simplex virus by optical super-resolution imaging. Nat Commun 6, 5980.

Le Sage, V., Jung, M., Alter, J.D., Wills, E.G., Johnston, S.M., Kawaguchi, Y., Baines, J.D., and Banfield, B.W. (2013). The Herpes Simplex Virus Type 2 UL21 Protein is Essential for Virus Propagation. J Virol.

Lee, J.H., Vittone, V., Diefenbach, E., Cunningham, A.L., and Diefenbach, R.J. (2008). Identification of structural protein-protein interactions of herpes simplex virus type 1 . Virology 378, 347-354.

Lee, J.I., Luxton, G.W., and Smith, G.A. (2006). Identification of an essential domain in the herpesvirus VP1/2 tegument protein: the carboxy terminus directs incorporation into capsid assemblons. J Virol 80, 12086-12094. 
Lee, J.I., Sollars, P.J., Baver, S.B., Pickard, G.E., Leelawong, M., and Smith, G.A. (2009). A herpesvirus encoded deubiquitinase is a novel neuroinvasive determinant. PLoS Pathog 5, e1000387.

Lewis, P., Fu, Y., and Lentz, T.L. (2000). Rabies virus entry at the neuromuscular junction in nerve-muscle cocultures. Muscle Nerve 23, 720-730.

Liu, J.J., Ding, J., Kowal, A.S., Nardine, T., Allen, E., Delcroix, J.D., Wu, C., Mobley, W., Fuchs, E., and Yang, Y. (2003). BPAG1n4 is essential for retrograde axonal transport in sensory neurons. J Cell Biol 163, 223-229.

Liu, X., and Cohen, J.I. (2015). The role of PI3K/Akt in human herpesvirus infection: From the bench to the bedside. Virology 479-480, 568-577.

Liu, X., Fitzgerald, K., Kurt-Jones, E., Finberg, R., and Knipe, D.M. (2008). Herpesvirus tegument protein activates NF-kappaB signaling through the TRAF6 adaptor protein. Proc Natl Acad Sci U S A 105, 11335-11339.

Liu, Y.-T., Jiang, J., Bohannon, K.P., Dai, X., Luxton, G.W., Hui, W.H., Bi, G.-Q., Smith, G.A., and Zhou, Z.H. (2017). A pUL25 dimer interfaces the pseudorabies virus capsid and tegument. J Gen Virol 98, 2837-2849.

Loret, S., Guay, G., and Lippe, R. (2008). Comprehensive characterization of extracellular herpes simplex virus type 1 virions. J Virol 82, 8605-8618.

Luby-Phelps, K. (1994). Physical properties of cytoplasm. Curr Opin Cell Biol 6, 3-9.

Luby-Phelps, K. (2000). Cytoarchitecture and physical properties of cytoplasm: volume, viscosity, diffusion, intracellular surface area. Int Rev Cytol 192, 189-221.

Luxton, G.W., Haverlock, S., Coller, K.E., Antinone, S.E., Pincetic, A., and Smith, G.A. (2005). Targeting of herpesvirus capsid transport in axons is coupled to association with specific sets of tegument proteins. Proc Natl Acad Sci U S A 102, 5832-5837.

Lycke, E., Hamark, B., Johansson, M., Krotochwil, A., Lycke, J., and Svennerholm, B. (1988). Herpes simplex virus infection of the human sensory neuron. An electron microscopy study. Arch Virol 101, 87-104. 
Lycke, E., Kristensson, K., Svennerholm, B., Vahlne, A., and Ziegler, R. (1984). Uptake and transport of herpes simplex virus in neurites of rat dorsal root ganglia cells in culture. J Gen Virol 65, 55-64.

Maekawa, M., Ishizaki, T., Boku, S., Watanabe, N., Fujita, A., Iwamatsu, A., Obinata, T., Ohashi, K., Mizuno, K., and Narumiya, S. (1999). Signaling from Rho to the actin cytoskeleton through protein kinases ROCK and LIM-kinase. Science 285, 895-898.

Maier, O., Sollars, P.J., Pickard, G.E., and Smith, G.A. (2016). Visualizing herpesvirus procapsids in living cells. J Virol 90, 10182-10192.

Maringer, K., and Elliott, G. (2010). Recruitment of herpes simplex virus type 1 immediate-early protein ICP0 to the virus particle. J Virol 84, 4682-4696.

Marzo, M.G., Griswold, J.M., and Markus, S.M. (2020). Pac1/LIS1 stabilizes an uninhibited conformation of dynein to coordinate its localization and activity. Nat Cell Biol 22, 559-569.

Maurer, U.E., Sodeik, B., and Grunewald, K. (2008). Native 3D intermediates of membrane fusion in herpes simplex virus 1 entry. Proc Natl Acad Sci U S A 105, 10559-10564.

Mbong, E.F., Woodley, L., Frost, E., Baines, J.D., and Duffy, C. (2012). Deletion of UL21 causes a delay in early stages of the herpes simplex virus type 1 replication cycle. J Virol.

McElwee, M., Beilstein, F., Labetoulle, M., Rixon, F.J., and Pasdeloup, D. (2013). Dystonin/BPAG1 Promotes Plus-End-Directed Transport of Herpes Simplex Virus 1 Capsids on Microtubules during Entry. J Virol 87, 11008-11018.

McElwee, M., Vijayakrishnan, S., Rixon, F., and Bhella, D. (2018). Structure of the herpes simplex virus portal-vertex. PLoS Biol 16, e2006191.

McNab, A.R., Desai, P., Person, S., Roof, L.L., Thomsen, D.R., Newcomb, W.W., Brown, J.C., and Homa, F.L. (1998). The product of the herpes simplex virus type 1 UL25 gene is required for encapsidation but not for cleavage of replicated viral DNA. J Virol 72, 1060-1070.

Meckes, D.G., Jr., and Wills, J.W. (2007). Dynamic interactions of the UL16 tegument protein with the capsid of herpes simplex virus. J Virol 81, 13028-13036. 
Meckes, D.G., Jr., and Wills, J.W. (2008). Structural rearrangement within an enveloped virus upon binding to the host cell. J Virol 82, 10429-10435.

Michael, K., Bottcher, S., Klupp, B.G., Karger, A., and Mettenleiter, T.C. (2006). Pseudorabies virus particles lacking tegument proteins pUL11 or pUL16 incorporate less full-length pUL36 than wild-type virus, but specifically accumulate a pUL36 N-terminal fragment. J Gen Virol 87, 3503-3507.

Morgan, C., Ellison, S.A., Rose, H.M., and Moore, D.H. (1953). Electron microscopic examination of inclusion bodies of herpes simplex virus. Proc Soc Exp Biol Med 82, 454-457.

Morrison, E.E., Wang, Y.F., and Meredith, D.M. (1998). Phosphorylation of structural components promotes dissociation of the herpes simplex virus type 1 tegument. J Virol 72, 7108-7114.

Nagel, C.H., Dohner, K., Binz, A., Bauerfeind, R., and Sodeik, B. (2012). Improper tagging of the non-essential small capsid protein VP26 impairs nuclear capsid egress of herpes simplex virus. PLoS One 7, e44177.

Newcomb, W.W., and Brown, J.C. (2009). Time-dependent transformation of the herpesvirus tegument. J Virol 83, 8082-8089.

Newcomb, W.W., and Brown, J.C. (2010). Structure and capsid association of the herpesvirus large tegument protein UL36. J Virol 84, 9408-9414.

Newcomb, W.W., Homa, F.L., Thomsen, D.R., Booy, F.P., Trus, B.L., Steven, A.C., Spencer, J.V., and Brown, J.C. (1996). Assembly of the herpes simplex virus capsid: characterization of intermediates observed during cell-free capsid formation. J Mol Biol 263, 432-446.

Newcomb, W.W., Juhas, R.M., Thomsen, D.R., Homa, F.L., Burch, A.D., Weller, S.K., and Brown, J.C. (2001). The UL6 gene product forms the portal for entry of DNA into the herpes simplex virus capsid. J Virol 75, 10923-10932.

Newcomb, W.W., Trus, B.L., Booy, F.P., Steven, A.C., Wall, J.S., and Brown, J.C. (1993). Structure of the herpes simplex virus capsid. Molecular composition of the pentons and the triplexes. J Mol Biol 232, 499-511.

Newcomb, W.W., Trus, B.L., Cheng, N., Steven, A.C., Sheaffer, A.K., Tenney, D.J., Weller, S.K., and Brown, J.C. (2000). Isolation of herpes simplex virus 
procapsids from cells infected with a protease-deficient mutant virus. J Virol 74, 1663-1673.

Nicola, A.V., and Straus, S.E. (2004). Cellular and viral requirements for rapid endocytic entry of herpes simplex virus. J Virol 78, 7508-7517.

Nishioka, Y., and Silverstein, S. (1978). Requirement of protein synthesis for the degradation of host mRNA in Friend erythroleukemia cells infected wtih herpes simplex virus type 1. J Virol 27, 619-627.

O'Hara, M., Rixon, F.J., Stow, N.D., Murray, J., Murphy, M., and Preston, V.G. (2010). Mutational analysis of the herpes simplex virus type 1 UL25 DNA packaging protein reveals regions that are important after the viral DNA has been packaged. J Virol 84, 4252-4263.

Oh, M.J., Akhtar, J., Desai, P., and Shukla, D. (2010). A role for heparan sulfate in viral surfing. Biochem Biophys Res Commun 391, 176-181.

Ohka, S., Matsuda, N., Tohyama, K., Oda, T., Morikawa, M., Kuge, S., and Nomoto, A. (2004). Receptor (CD155)-dependent endocytosis of poliovirus and retrograde axonal transport of the endosome. J Virol 78, 7186-7198.

Ohka, S., Yang, W.X., Terada, E., Iwasaki, K., and Nomoto, A. (1998). Retrograde transport of intact poliovirus through the axon via the fast transport system. Virology 250, 67-75.

Ojala, P.M., Sodeik, B., Ebersold, M.W., Kutay, U., and Helenius, A. (2000). Herpes simplex virus type 1 entry into host cells: reconstitution of capsid binding and uncoating at the nuclear pore complex in vitro. Mol Cell Biol 20, 4922-4931.

Onomoto, K., Yoneyama, M., Fung, G., Kato, H., and Fujita, T. (2014). Antiviral innate immunity and stress granule responses. Trends Immunol 35, 420-428.

Owen, D.J., Crump, C.M., and Graham, S.C. (2015). Tegument assembly and secondary envelopment of alphaherpesviruses. Viruses 7, 5084-5114.

Pasdeloup, D., Blondel, D., Isidro, A.L., and Rixon, F.J. (2009). Herpesvirus Capsid Association To The Nuclear Pore Complex And Viral DNA Release Involve The Nucleoporin CAN/Nup214 And The Capsid Protein pUL25. J Virol 83, 6610-6623.

Pasdeloup, D., McElwee, M., Beilstein, F., Labetoulle, M., and Rixon, F.J. (2013). Herpesvirus tegument protein pUL37 interacts with dystonin/BPAG1 
to promote capsid transport on microtubules during egress. J Virol 87, 2857-2867.

Patel, A., Hanson, J., McLean, T.I., Olgiate, J., Hilton, M., Miller, W.E., and Bachenheimer, S.L. (1998). Herpes simplex type 1 induction of persistent NF-kappa B nuclear translocation increases the efficiency of virus replication. Virology 247, 212-222.

Person, S., and Desai, P. (1998). Capsids are formed in a mutant virus blocked at the maturation site of the UL26 and UL26.5 open reading frames of herpes simplex virus type 1 but are not formed in a null mutant of UL38 (VP19C). Virology 242, 193-203.

Pickard, G.E., Brodersen, B., Sollars, P.J., and Smith, G.A. (2020). The pseudorabies virus $R 2$ non-neuroinvasive vaccine: A proof-of-concept study in pigs. Vaccine $38,4524-4528$.

Pitts, J.D., Klabis, J., Richards, A.L., Smith, G.A., and Heldwein, E.E. (2014). Crystal structure of the herpesvirus inner tegument protein UL37 supports its essential role in control of viral trafficking. J Virol 88, 5462-5473.

Poliakova, K., Adebola, A., Leung, C.L., Favre, B., Liem, R.K., Schepens, I., and Borradori, L. (2014). BPAG1a and b associate with EB1 and EB3 and modulate vesicular transport, Golgi apparatus structure, and cell migration in C2.7 myoblasts. PLoS One 9, e107535.

Poon, A.P., and Roizman, B. (1993). Characterization of a temperaturesensitive mutant of the UL15 open reading frame of herpes simplex virus 1 . J Virol 67, 4497-4503.

Preston, V.G., Murray, J., Preston, C.M., McDougall, I.M., and Stow, N.D. (2008). The UL25 gene product of herpes simplex virus type 1 is involved in uncoating of the viral genome. J Virol 82, 6654-6666.

Purves, F.C., Longnecker, R.M., Leader, D.P., and Roizman, B. (1987). Herpes simplex virus 1 protein kinase is encoded by open reading frame US3 which is not essential for virus growth in cell culture. J Virol 61, 2896-2901.

Radtke, K., Kieneke, D., Wolfstein, A., Michael, K., Steffen, W., Scholz, T., Karger, A., and Sodeik, B. (2010). Plus- and minus-end directed microtubule motors bind simultaneously to herpes simplex virus capsids using different inner tegument structures. PLoS Pathog 6, e1000991. 
Read, G.S., and Frenkel, N. (1983). Herpes simplex virus mutants defective in the virion-associated shutoff of host polypeptide synthesis and exhibiting abnormal synthesis of alpha (immediate early) viral polypeptides. J Virol 46, 498-512.

Reck-Peterson, S.L., Redwine, W.B., Vale, R.D., and Carter, A.P. (2018). The cytoplasmic dynein transport machinery and its many cargoes. Nat Rev Mol Cell Biol 19, 382-398.

Ren, R., and Racaniello, V.R. (1992). Poliovirus spreads from muscle to the central nervous system by neural pathways. J Infect Dis 166, 747-752.

Richards, A.L., Sollars, P.J., Pitts, J.D., Stults, A.M., Heldwein, E.E., Pickard, G.E., and Smith, G.A. (2017). The pUL37 tegument protein guides alphaherpesvirus retrograde axonal transport to promote neuroinvasion. PLoS Pathog 13, e1006741.

Rixon, F.J., and McNab, D. (1999). Packaging-competent capsids of a herpes simplex virus temperature-sensitive mutant have properties similar to those of in vitro-assembled procapsids. J Virol 73, 5714-5721.

Roberts, A.P., Abaitua, F., O'Hare, P., McNab, D., Rixon, F.J., and Pasdeloup, D. (2009). Differing roles of inner tegument proteins pUL36 and pUL37 during entry of herpes simplex virus type 1. J Virol 83, 105-116.

Rode, K., Dohner, K., Binz, A., Glass, M., Strive, T., Bauerfeind, R., and Sodeik, B. (2011). Uncoupling uncoating of herpes simplex virus genomes from their nuclear import and gene expression. J Virol 85, 4271-4283.

Romero, N., Van Waesberghe, C., and Favoreel, H.W. (2020). Pseudorabies virus infection of epithelial cells leads to persistent but aberrant activation of the NF-kappaB pathway, inhibiting hallmark NF-kappaB-induced proinflammatory gene expression. J Virol.

Roos, W.H., Radtke, K., Kniesmeijer, E., Geertsema, H., Sodeik, B., and Wuite, G.J. (2009). Scaffold expulsion and genome packaging trigger stabilization of herpes simplex virus capsids. Proc Natl Acad Sci U S A 106, 9673-9678.

Ruhge, L.L., Huet, A.G.E., Conway, J.F., and Smith, G.A. (2018). The apical region of the herpes simplex virus major capsid protein promotes capsid maturation. J Virol 92, e00821-00818. 
Salinas, S., Schiavo, G., and Kremer, E.J. (2010). A hitchhiker's guide to the nervous system: the complex journey of viruses and toxins. Nat Rev Microbiol 8, 645-655.

Sandbaumhuter, M., Dohner, K., Schipke, J., Binz, A., Pohlmann, A., Sodeik, B., and Bauerfeind, R. (2013). Cytosolic herpes simplex virus capsids not only require binding inner tegument protein pUL36 but also pUL37 for active transport prior to secondary envelopment. Cell Microbiol 15, 248-269.

Schipke, J., Pohlmann, A., Diestel, R., Binz, A., Rudolph, K., Nagel, C.H., Bauerfeind, R., and Sodeik, B. (2012). The C-terminus of the large tegument protein pUL36 contains multiple capsid binding sites that function differently during assembly and cell entry of herpes simplex virus. J Virol 86, 3682-3700.

Schlieker, C., Weihofen, W.A., Frijns, E., Kattenhorn, L.M., Gaudet, R., and Ploegh, H.L. (2007). Structure of a herpesvirus-encoded cysteine protease reveals a unique class of deubiquitinating enzymes. Mol Cell 25, 677-687.

Schmid, M.F., Hecksel, C.W., Rochat, R.H., Bhella, D., Chiu, W., and Rixon, F.J. (2012). A Tail-like assembly at the portal vertex in intact herpes simplex type-1 virions. PLoS Pathog 8, e1002961.

Scholtes, L.D., Yang, K., Li, L.X., and Baines, J.D. (2010). The capsid protein encoded by UL17 of herpes simplex virus 1 interacts with the tegument protein VP13/14. J Virol.

Schuster, M., Kilaru, S., Ashwin, P., Lin, C., Severs, N.J., and Steinberg, G. (2011). Controlled and stochastic retention concentrates dynein at microtubule ends to keep endosomes on track. EMBO J 30, 652-664.

Scrima, N., Lepault, J., Boulard, Y., Pasdeloup, D., Bressanelli, S., and Roche, S. (2015). Insights into herpesvirus tegument organization from structural analyses of the 970 central residues of HSV-1 UL36 protein. J Biol Chem 290, 8820-8833.

Scrivano, L., Sinzger, C., Nitschko, H., Koszinowski, U.H., and Adler, B. (2011). HCMV spread and cell tropism are determined by distinct virus populations. PLoS Pathog 7, e1001256.

Sekine, E., Schmidt, N., Gaboriau, D., and O'Hare, P. (2017). Spatiotemporal dynamics of HSV genome nuclear entry and compaction state transitions 
using bioorthogonal chemistry and super-resolution microscopy. PLoS Pathog 13, e1006721.

Sheaffer, A.K., Newcomb, W.W., Gao, M., Yu, D., Weller, S.K., Brown, J.C., and Tenney, D.J. (2001). Herpes simplex virus DNA cleavage and packaging proteins associate with the procapsid prior to its maturation. J Virol 75 , 687-698.

Smith, G. (2012). Herpesvirus Transport to the Nervous System and Back Again. Annu Rev Microbiol 66, 153-176.

Smith, G.A. (2017). Assembly and egress of an alphaherpesvirus clockwork. Adv Anat Embryol Cell Biol 223, 171-193.

Smith, G.A., and Enquist, L.W. (1999). Construction and transposon mutagenesis in Escherichia coli of a full-length infectious clone of pseudorabies virus, an alphaherpesvirus. J Virol 73, 6405-6414.

Smith, G.A., Pomeranz, L., Gross, S.P., and Enquist, L.W. (2004). Local modulation of plus-end transport targets herpesvirus entry and egress in sensory axons. Proc Natl Acad Sci U S A 101, 16034-16039.

Snijder, J., Radtke, K., Anderson, F., Scholtes, L., Corradini, E., Baines, J., Heck, A.J.R., Wuite, G.J.L., Sodeik, B., and Roos, W.H. (2017). VertexSpecific Proteins pUL17 and pUL25 Mechanically Reinforce Herpes Simplex Virus Capsids. J Virol 91.

Sodeik, B., Ebersold, M.W., and Helenius, A. (1997). Microtubule-mediated transport of incoming herpes simplex virus 1 capsids to the nucleus. J Cell Biol 136, 1007-1021.

Spear, P.G., and Roizman, B. (1972). Proteins specified by herpes simplex virus. V. Purification and structural proteins of the herpesvirion. J Virol 9, 143-159.

Stackpole, C.W. (1969). Herpes-type virus of the frog renal adenocarcinoma. I. Virus development in tumor transplants maintained at low temperature. J Virol 4, 75-93.

Stevenson, A.J., Morrison, E.E., Chaudhari, R., Yang, C.C., and Meredith, D.M. (1997). Processing and intracellular localization of the herpes simplex virus type 1 proteinase. J Gen Virol 78 ( Pt 3), 671-675. 
Strelow, L.I., and Leib, D.A. (1995). Role of the virion host shutoff (vhs) of herpes simplex virus type 1 in latency and pathogenesis. J Virol 69, 6779-6786.

Stringer, D.K., and Piper, R.C. (2011). A single ubiquitin is sufficient for cargo protein entry into MVBs in the absence of ESCRT ubiquitination. J Cell Biol 192, 229-242.

Strunze, S., Trotman, L.C., Boucke, K., and Greber, U.F. (2005). Nuclear targeting of adenovirus type 2 requires CRM1-mediated nuclear export. Mol Biol Cell 16, 2999-3009.

Stults, A.M., and Smith, G.A. (2019). The Herpes Simplex Virus 1 Deamidase Enhances Propagation but Is Dispensable for Retrograde Axonal Transport into the Nervous System. J Virol 93.

Suhanovsky, M.M., and Teschke, C.M. (2015). Nature's favorite building block: Deciphering folding and capsid assembly of proteins with the HK97-fold. Virology 479-480, 487-497.

Suomalainen, M., Nakano, M.Y., Keller, S., Boucke, K., Stidwill, R.P., and Greber, U.F. (1999). Microtubule-dependent plus- and minus end-directed motilities are competing processes for nuclear targeting of adenovirus. J Cell Biol 144, 657-672.

Svobodova, S., Bell, S., and Crump, C.M. (2012). Analysis of the interaction between the essential herpes simplex virus 1 tegument proteins VP16 and VP1/2. J Virol 86, 473-483.

Takakuwa, H., Goshima, F., Koshizuka, T., Murata, T., Daikoku, T., and Nishiyama, Y. (2001). Herpes simplex virus encodes a virion-associated protein which promotes long cellular processes in over-expressing cells. Genes Cells 6, 955-966.

Tian, J., Liu, Y., Liu, X., Sun, X., Zhang, J., and Qu, L. (2018). Feline Herpesvirus 1 US3 Blocks the Type I Interferon Signal Pathway by Targeting Interferon Regulatory Factor 3 Dimerization in a Kinase-Independent Manner. J Virol 92.

Tiwari, V., and Shukla, D. (2010). Phosphoinositide 3 kinase signalling may affect multiple steps during herpes simplex virus type-1 entry. J Gen Virol 91, 3002-3009. 
Topp, K.S., Bisla, K., Saks, N.D., and Lavail, J.H. (1996). Centripetal transport of herpes simplex virus in human retinal pigment epithelial cells in vitro. Neuroscience 71, 1133-1144.

Toropova, K., Huffman, J.B., Homa, F.L., and Conway, J.F. (2011). The Herpes Simplex Virus 1 UL17 Protein Is the Second Constituent of the Capsid Vertex-Specific Component Required for DNA Packaging and Retention. J Virol 85, 7513-7522.

Trus, B.L., Booy, F.P., Newcomb, W.W., Brown, J.C., Homa, F.L., Thomsen, D.R., and Steven, A.C. (1996). The herpes simplex virus procapsid: structure, conformational changes upon maturation, and roles of the triplex proteins VP19c and VP23 in assembly. J Mol Biol 263, 447-462.

Trus, B.L., Newcomb, W.W., Cheng, N., Cardone, G., Marekov, L., Homa, F.L., Brown, J.C., and Steven, A.C. (2007). Allosteric signaling and a nuclear exit strategy: binding of UL25/UL17 heterodimers to DNA-filled HSV-1 capsids. Mol Cell 26, 479-489.

Twarock, R., and Luque, A. (2019). Structural puzzles in virology solved with an overarching icosahedral design principle. Nat Commun 10, 4414.

Uetz, P., Dong, Y.A., Zeretzke, C., Atzler, C., Baiker, A., Berger, B., Rajagopala, S.V., Roupelieva, M., Rose, D., Fossum, E., et al. (2006). Herpesviral protein networks and their interaction with the human proteome. Science 311, 239-242.

Van den Broeke, C., Jacob, T., and Favoreel, H.W. (2014). Rho'ing in and out of cells: viral interactions with Rho GTPase signaling. Small GTPases 5, e28318.

Vittone, V., Diefenbach, E., Triffett, D., Douglas, M.W., Cunningham, A.L., and Diefenbach, R.J. (2005). Determination of interactions between tegument proteins of herpes simplex virus type 1. J Virol 79, 9566-9571.

Waisner, H., and Kalamvoki, M. (2019). The ICPO protein of herpes simplex virus 1 (HSV-1) down-regulates major autophagy adaptor proteins, sequestosome 1 (SQSTM1/p62) and optineurin (OPTN), during the early stages of HSV-1 infection. J Virol. 
Wang, I.H., Burckhardt, C.J., Yakimovich, A., Morf, M.K., and Greber, U.F. (2017). The nuclear export factor CRM1 controls juxta-nuclear microtubuledependent virus transport. J Cell Sci 130, 2185-2195.

Wang, J., Yuan, S., Zhu, D., Tang, H., Wang, N., Chen, W., Gao, Q., Li, Y., Wang, J., Liu, H., et al. (2018). Structure of the herpes simplex virus type 2 C-capsid with capsid-vertex-specific component. Nat Commun 9, 3668.

Wikoff, W.R., Liljas, L., Duda, R.L., Tsuruta, H., Hendrix, R.W., and Johnson, J.E. (2000). Topologically linked protein rings in the bacteriophage HK97 capsid. Science 289, 2129-2133.

Wolfstein, A., Nagel, C.H., Radtke, K., Dohner, K., Allan, V.J., and Sodeik, B. (2006). The inner tegument promotes herpes simplex virus capsid motility along microtubules in vitro. Traffic 7, 227-237.

Wu, F., Xing, J., Wang, S., Li, M., and Zheng, C. (2011). Screening and identification of host factors interacting with UL14 of herpes simplex virus 1. Medical microbiology and immunology 200, 203-208.

Yamauchi, Y., Kiriyama, K., Kubota, N., Kimura, H., Usukura, J., and Nishiyama, Y. (2008). The UL14 tegument protein of herpes simplex virus type 1 is required for efficient nuclear transport of the alpha transinducing factor VP16 and viral capsids. J Virol 82, 1094-1106.

Yamauchi, Y., Wada, K., Goshima, F., Takakuwa, H., Daikoku, T., Yamada, M., and Nishiyama, Y. (2001). The UL14 protein of herpes simplex virus type 2 translocates the minor capsid protein VP26 and the DNA cleavage and packaging UL33 protein into the nucleus of coexpressing cells. J Gen Virol 82, 321-330.

Yan, K., Liu, J., Guan, X., Yin, Y.X., Peng, H., Chen, H.C., and Liu, Z.F. (2019).

The Carboxyl Terminus of Tegument Protein pUL21 Contributes to Pseudorabies Virus Neuroinvasion. J Virol 93.

Yao, F., and Courtney, R.J. (1992). Association of ICP0 but not ICP27 with purified virions of herpes simplex virus type 1. J Virol 66, 2709-2716.

Yuan, S., Wang, J., Zhu, D., Wang, N., Gao, Q., Chen, W., Tang, H., Wang, J., Zhang, X., Liu, H., et al. (2018). Cryo-EM structure of a herpesvirus capsid at 3.1 A. Science 360 . 
Zaichick, S.V., Bohannon, K.P., Hughes, A., Sollars, P.J., Pickard, G.E., and Smith, G.A. (2013). The herpesvirus VP1/2 protein is an effector of dyneinmediated capsid transport and neuroinvasion. Cell Host Microbe 13, 193-203.

Zhang, J., Zhao, J., Xu, S., Li, J., He, S., Zeng, Y., Xie, L., Xie, N., Liu, T., Lee, K., et al. (2018). Species-Specific Deamidation of cGAS by Herpes Simplex Virus UL37 Protein Facilitates Viral Replication. Cell Host Microbe 24, 234-248 e235.

Zhang, Z., Selariu, A., Warden, C., Huang, G., Huang, Y., Zaccheus, O., Cheng, T., Xia, N., and Zhu, H. (2010). Genome-wide mutagenesis reveals that ORF7 is a novel VZV skin-tropic factor. PLoS Pathog 6, e1000971.

Zhao, J., Zeng, Y., Xu, S., Chen, J., Shen, G., Yu, C., Knipe, D., Yuan, W., Peng, J., Xu, W., et al. (2016). A viral deamidase targets the helicase domain of RIG-I to block RNA-induced activation. Cell Host Microbe 20, 770-784.

Zheng, K., Xiang, Y., Wang, X., Wang, Q., Zhong, M., Wang, S., Wang, X., Fan, J., Kitazato, K., and Wang, Y. (2014). Epidermal growth factor receptor-PI3K signaling controls cofilin activity to facilitate herpes simplex virus 1 entry into neuronal cells. mBio 5, e00958-00913.

Zhou, J., Scherer, J., Yi, J., and Vallee, R.B. (2018). Role of kinesins in directed adenovirus transport and cytoplasmic exploration. PLoS Pathog 14, e1007055.

Zhou, Z.H., Chen, D.H., Jakana, J., Rixon, F.J., and Chiu, W. (1999). Visualization of tegument-capsid interactions and DNA in intact herpes simplex virus type 1 virions. J Virol 73, 3210-3218. 